Published in final edited form as:

Nat Rev Immunol. 2013 April ; 13(4): 227-242. doi:10.1038/nri3405.

\title{
Molecular mechanisms of $\mathrm{T}$ cell co-stimulation and co-inhibition
}

\author{
Lieping Chen ${ }^{1}$ and Dallas B. Flies ${ }^{1,2}$ \\ ${ }^{1}$ Department of Immunobiology and Yale Cancer Center, Yale University School of Medicine, \\ New Haven, Connecticut 06519, USA
}

\begin{abstract}
Co-stimulatory and co-inhibitory receptors have a pivotal role in T cell biology, as they determine the functional outcome of $\mathrm{T}$ cell receptor (TCR) signalling. The classic definition of T cell costimulation continues to evolve through the identification of new co-stimulatory and co-inhibitory receptors, the biochemical characterization of their downstream signalling events and the delineation of their immunological functions. Notably, it has been recently appreciated that costimulatory and co-inhibitory receptors display great diversity in expression, structure and function, and that their functions are largely context dependent. Here, we focus on some of these emerging concepts and review the mechanisms through which $\mathrm{T}$ cell activation, differentiation and function is controlled by co-stimulatory and co-inhibitory receptors.
\end{abstract}

The specific recognition of cognate antigenic peptides presented by MHC molecules triggers $\mathrm{T}$ cell receptor (TCR) signalling, but it is co-stimulatory and co-inhibitory receptors (here collectively named co-signalling receptors for simplicity) on $\mathrm{T}$ cells that direct $\mathrm{T}$ cell function and determine $\mathrm{T}$ cell fate. The discovery of $\mathrm{CD} 28$ as a prototype co-stimulatory TCR (BOX 1) provided evidence for the two-signal model of T cell activation, according to which both TCR and co-stimulatory signalling are required for full $\mathrm{T}$ cell activation ${ }^{1-3}$. Since then, T cell co-signalling receptors have been broadly defined as cell-surface molecules that can transduce signals into $\mathrm{T}$ cells to positively (co-stimulatory receptors) or negatively (co-inhibitory receptors) modulate TCR signalling.

The repertoire of co-signalling receptors expressed on $\mathrm{T}$ cells is highly versatile and responsive to changes in the tissue environment. Within a specific tissue environment, the signals that are received from or, sometimes, transduced to the surrounding cells by the given repertoire of $\mathrm{T}$ cell co-signalling receptors are determined by the type of ligands or counter-receptors that are expressed on the surface of the cells that interact with T cells. Cosignalling ligands and counter-receptors have now been identified on nearly all cell types, although their expression has been most well characterized on professional antigenpresenting cells (APCs), as APCs are the primary drivers of T cell activation and differentiation in lymphoid organs ${ }^{4}$.

(C) 2013 Macmillan Publishers Limited. All rights reserved

Correspondence to L.C.lieping.chen@yale.edu.

${ }^{2}$ Present address: Department of Obstetrics and Gynecology, University of New Mexico, Albuquerque, New Mexico 87131, USA.

Competing interests statement

The authors declare no competing financial interests

FURTHER INFORMATION

Lieping chen's homepage: http://www.immunobiology.yale.edu/people/lieping_chen.profile

SUPPLEMENTARY INFORMATION

S1 (table) | S2 (table) 
It is now clear that co-signalling molecules have a crucial role in regulating $\mathrm{T}$ cell activation, subset differentiation, effector function and survival. Following recognition of cognate peptide-MHC complexes on APCs by the TCR, co-signalling receptors often colocalize with TCR molecules at the immunological synapse (BOX 2), where they synergize with TCR signalling to promote or inhibit T cell activation and function ${ }^{5}$. In this interactive environment, functionally diverse costimulatory and co-inhibitory molecules are expressed in overlapping spatiotemporal fashion. Whereas relatively little is known about how diverse co-signalling pathways truly integrate, a great deal is now known concerning the function of individual co-signalling molecules in specific phases of $\mathrm{T}$ cell responses.

As our understanding of co-signalling continues to progress, the classical two-signal model, originally represented by the B7-CD28 paradigm (BOX 1), needs to be revisited to encompass the complex mechanisms involved in T cell co-signalling. In this Review we focus on how the concept of co-signalling in T cells has evolved. In this context, recent work describing new molecular interactions, biochemical signalling pathways and the diverse roles of co-signalling in $\mathrm{T}$ cell activation, differentiation, effector function and survival are highlighted.

\section{T cell co-signalling receptor superfamilies}

Most co-signalling molecules are members of the immunoglobulin superfamily (IgSF) and tumour necrosis factor receptor superfamily (TNFRSF). Co-signalling molecules can be further subdivided into specific families on the basis of primary amino acid sequence, protein structure and function (Supplementary information S1,S2 (tables)).

\section{Co-signalling receptors of the immunoglobulin super-family}

The IgSF includes several co-signalling families (Supplementary information S1 (table)). The CD28 and B7 families are perhaps the most well-described families of IgSF receptors. The members of the CD28 family interact primarily with members of the B7 family 6 with two exceptions: the co-inhibitory receptor B and T lymphocyte attenuator (BTLA) binds to the TNFRSF member herpes virus entry mediator (HVEM; also known as TNFRSF14) ${ }^{7,8}$, and B7-H6 (also known as NCR3LG1) binds to natural killer cell p30-related protein (NKp30; also known as NCR3) of the natural cytotoxicity receptor family in humans ${ }^{9}$.

The type I transmembrane (or T cell) immunoglobulin and mucin (TIM) domain-containing molecules are a family of IgSF co-signalling receptors that are uniquely composed of both an IgV-like domain and a mucin-like domain ${ }^{10}$. TIM family members have been shown to have both co-stimulatory and co-inhibitory functions ${ }^{11}$. CD2/signalling lymphocytic activation molecule (SLAM) family members are IgSF molecules with an $\operatorname{IgV}$ and an $\operatorname{IgC}$ domain that engage primarily in homophilic or heterophilic interactions ${ }^{10}$. On T cells, CD2 and SLAM function as co-stimulatory receptors ${ }^{12,13}$, whereas $2 \mathrm{~B} 4$ and LY108 have recently been shown to function primarily as co-inhibitory receptors ${ }^{14-16}$; the CD2/SLAM family is reviewed in detail elsewhere ${ }^{13,17}$. Butyrophilin (BTN) and BTN-like (BTNL) family molecules have extracellular structures similar to those of B7 family molecules; however, their cytoplasmic tails contain a canonical b30.2-RING (really interesting new gene) domain with unknown function ${ }^{18}$. Therefore, the co-signalling function of BTN and BTNL molecules remains to be determined.

In addition, several other IgSF molecules have been identified that function as co-signalling molecules. Lymphocyte activation gene 3 protein (LAG3; also known as CD223) is a molecule with homology to CD4 that functions as a co-inhibitory molecule. LAG3 interacts with MHC class II molecules, and probably also with other unidentified molecules ${ }^{19}$. The receptors CD226 (also known as DNAM1), T cell immunoreceptor with immunoglobulin 
and ITIM domains (TIGIT; also known as VSIG9), cytotoxic and regulatory T cell molecule (CRTAM) and CD96 (also known as TACTILE) all interact with nectin and nectin-like ligands ${ }^{20}$. CD226 and CRTAM are co-stimulatory, TIGIT is co-inhibitory and the role of CD96 remains unclear. Leukocyte-associated immunoglobulin-like receptor 1 (LAIR1; also known as CD305) is a member of the LAIR family containing a single C2-type immunoglobulin-like domain that binds collagens and has a co-inhibitory function ${ }^{21}$. Finally, CD160 is a glycosylphosphatidylinositol-anchored molecule containing a single IgV-like domain that binds to HVEM and functions as a co-inhibitory receptor on $\mathrm{T}$ cells ${ }^{22}$.

The identification of co-stimulatory and co-inhibitory receptors from diverse IgSF families attests to the heterogeneity of both the structural interactions among co-signalling molecules and their functional outcomes.

\section{Co-signalling receptors of the TNF receptor superfamily}

TNFRSF receptors contain one or more extracellular cysteine-rich domains (CRDs), whereas their ligands contain a conserved extracellular TNF homology domain (THD) ${ }^{10,23}$ (Supplementary information S2(table)). Although co-signalling receptors of the TNFRSF were historically divided into subfamilies based on the sequence and structure of the THDs of their interacting ligands, a recently described classification system takes into consideration both receptor CRDs and ligand THDs ${ }^{10,23}$. Family classification remains similar in both systems, but the new classification system uses a structure-based sequence clustering method to offer insight into structure-dependent interactions and the co-evolution of TNF receptors and ligands ${ }^{23}$.

The classification of TNFRSF co-signalling receptors on the basis of their structure seems to have little correlation with their co-signalling function. For example, although all members of the type-L, or conventional, family share similar CRD architecture, only some of them, including HVEM, death receptor 3 (DR3; also known as TNFRSF25), CD40 (also known as TNFRSF5) and lymphotoxin- $\beta$ receptor (LTBR; also known as TNFRSF3), have a costimulatory function, whereas other type L-family receptors have functions in diverse processes other than co-signalling ${ }^{24}$. Similarly, the type-S (also known as EF-disulphide) family receptors transmembrane activator and CAML interactor (TACI; also known as TNFRSF13B), B cell-activating factor receptor (BAFFR; also known as TNFRSF13C) and B cell maturation protein (BCMA; also known as TNFRSF17) interact with the ligands a proliferation-inducing ligand (APRIL; also known as TNFSF13) and B cell-activating factor (BAFF; also known as TNFSF13B) to co-stimulate B cells, whereas the type-S family members TWEAK receptor (TWEAKR; also known as TNFRSF12A), ectodysplasin-A receptor (EDAR) and X-linked ectodysplasin-A receptor (XEDAR; also known as TNFRSF27) do not function primarily as co-stimulatory or co-inhibitory receptors ${ }^{24}$. By contrast, all receptors of the type- $\mathrm{V}$, or divergent, family — including 4-1BB (also known as CD137 or TNFRSF9), OX40 (also known as TNFSF4), CD27 (also known as TNFRSF7), glucocorticoid-induced TNFR-related protein (GITR; also known as TNFRSF18) and CD30 (also known as TNFRSF8) - function primarily as co-stimulatory molecules ${ }^{24}$. Finally, the co-signalling function of the orphan TNF receptors nerve growth factor receptor (NGFR; also known as TNFRSF16), TROY (also known as TNFRSF19), receptor expressed in lymphoid tissues (RELT; also known as TNFRSF19L) and DR6 (also known as TNFRSF21) remains elusive, although some evidence exists that RELT can co-stimulate $T$ cells ${ }^{25}$.

Thus, similarly to the IgSF co-stimulatory and co-inhibitory receptors, TNFRSF cosignalling molecules are structurally diverse. It is noteworthy that the classification of TNFRSF co-signalling receptors and ligands, based on structure alone, may provide a guide 
for identifying new potential co-stimulatory and co-inhibitory molecules but is insufficient to characterize their co-signalling function.

\section{Re-examining the co-signalling paradigm Spatiotemporal regulation of co-signalling}

There are several levels of regulation in T cell co-signalling. Modulation of cell surface expression is a primary mode of co-signalling control, whereas the differential expression patterns of receptor-ligand pairs function is a secondary level of co-signalling regulation. For example, the co-stimulatory molecule HVEM is broadly expressed on haematopoietic and non-haematopoietic cells, but expression of its counter-receptor LIGHT (also known as TNFSF14) is highly restricted to APCs and T cells ${ }^{22}$. In addition, expression of both HVEM and LIGHT on the same T cell has not been observed. HVEM is constitutively expressed on naive $\mathrm{T}$ cells and downregulated following $\mathrm{T}$ cell activation, only to be re-expressed later on effector and memory $\mathrm{T}$ cells ${ }^{22}$. By contrast, LIGHT is upregulated following T cell priming and is expressed on activated $\mathrm{T}$ cells, but is later down-regulated ${ }^{22}$. It has been suggested that these two molecules are reciprocally regulated to avoid cis interactions on the T cell surface, although precisely how this regulation is achieved remains unclear ${ }^{22}$.

Clearly, the dynamics of co-stimulatory and co-inhibitory molecule expression on the cell surface are primarily regulated transcriptionally and post-transcriptionally in most cases, but other mechanisms of regulation may also exist. For instance, cell surface expression of B7-1 (also known as CD80) and B7-2 (also known as CD86) is downregulated through transendocytosis by cytotoxic T lymphocyte antigen 4 (CTLA4). During this process CTLA4 rips B7 molecules from the surface of APCs, thereby preventing interactions of B7 molecules with the co-stimulatory molecule CD28 (REF. 26).

Notably, it is now evident that the expression of many co-stimulatory and co-inhibitory molecules on the surface of T cells is induced following activation and that changes in the cell surface expression of many molecules occur in overlapping fashion as $\mathrm{T}$ cells proliferate and differentiate (TABLE 1). This observation has given rise to the concept of the tidal model of co-signalling, which we have proposed and described in detail previously ${ }^{27}$. In the tidal model of co-signalling, cell-surface interactions and subsequent intracellular signalling are continuously varied in response to dynamic environmental conditions. Indeed, T cell activation may be compared to the incoming tide, with an abundance of co-stimulatory receptors on naive and activated $\mathrm{T}$ cells pulling the $\mathrm{T}$ cell into functional responsiveness. At peak tide, both co-stimulatory and co-inhibitory molecules are expressed, and it is at this stage that functional $\mathrm{T}$ cell outcomes arise in the face of what often seem to be opposing molecular forces. As the tide recedes during the peak of $\mathrm{T}$ cell activation, the expression of co-stimulatory receptors is replaced by the expression of co-inhibitory receptors that function to suppress $\mathrm{T}$ cell activities. So, in contrast to the more concrete 'on/off' models of co-signalling often envisioned in the past, the tide model may better describe the fluid changes that are occurring in the transcriptional regulation, cell-surface profile and function of $\mathrm{T}$ cells over time.

\section{Differential interactions through multiple interfaces}

In addition to the spatiotemporal control of their expression patterns, the inherent structures of co-signalling receptors provide another level of regulation in $\mathrm{T}$ cell co-signalling ${ }^{10}$. Several co-signalling receptors interact with more than one ligand or counter-receptor, potentially through more than one binding site, and this results in multiple functions for a single co-signalling molecule (FIG. 1). The paradigm of the HVEM network illustrates how differential interactions occurring through multiple interfaces may determine the outcome of HVEM co-signalling. HVEM is composed of four CRDs: CRD2 and CRD3 are required for 
HVEM trimerization with the TNFRSF ligand LIGHT, which delivers a co-stimulatory signal to T cells through HVEM, whereas CRD1 and CRD2 bind BTLA and CD160 in a monomeric form and deliver an inhibitory signal to $\mathrm{T}$ cells ${ }^{22}$. In total, the HVEM network involves up to 14 different known molecular interactions, making this pathway highly complex (reviewed in detail in REFS 22,28).

Similarly, TIM family receptors, which are composed of an IgV domain and a mucin domain, may use these domains variably to interact with different ligands, resulting in distinct functional outcomes ${ }^{10}$. For example, it has been suggested that monoclonal antibodies binding to the IgV domain of TIM1 co-stimulate T cells, whereas monoclonal antibodies binding the mucin-like domain inhibit $\mathrm{T}$ cell responses. It remains to be determined whether differential interactions with endogenous ligands or counter-receptors through the $\operatorname{IgV}$ or the mucin domain determines the stimulatory or inhibitory potential of TIM family members in vivo ${ }^{11}$.

As another example of competing interactions through multiple interfaces, it was recently discovered that CD28 and CTLA4 bind a third ligand in humans, B7-H2, in addition to the classical CD28 and CTLA4 ligands B7-1 and B7-2 (REF. 29). B7-H2 is broadly inducible in peripheral tissues and is the only known binding partner for the co-stimulatory receptor inducible T cell co-stimulator (ICOS) ${ }^{30,31}$. The highly conserved MYPPPY motif of the proline-rich FG loop of CD28 and CTLA4 is crucial for binding the FG loop of B7-1 and B7-2, and an analogous FDPPPF motif on ICOS is essential for binding to B7-H2 (REF. 10) (FIG. 1d). However, CD28 and CTLA4 do not use the MYPPPY motif to bind B7-H2, although both CD28 and CTLA4 seem to bind an overlapping site on B7-H2 (REF. 29). These findings indicate that the CD28 and CTLA4 MYPPPY motif could interact with B7-1 or B7-2 while simultaneously interacting with $\mathrm{B} 7-\mathrm{H} 2$ through a unique binding site.

Conversely, ICOS, CD28 and CTLA4 may engage in competition for a similar binding site on B7-H2 (REF. 29). Finally, B7-H2 has been shown to co-stimulate T cells through both CD28 and ICOS, but ICOS binds to B7-H2 with significantly higher affinity than does CD28 or CTLA4 (REF. 29). Therefore the effects of these novel interactions in vivo in humans remain to be dissected.

In contrast to CD28 and CTLA4 interactions with B7-1 and B7-2 that occur primarily through the FG loops, analyses show that programmed cell death 1 (PD1) lacks both a wellorganized FG loop and the proline-rich XXPPPX motif present in CD28, CTLA4 and $\mathrm{ICOS}^{32,33}$. Therefore, PD1 interacts with the FG loops of B7-H1 (also known as PD1 ligand 1) and B7-DC (also known as PD1 ligand 2) through residues that are dispersed on the front sheet of the IgV domain ${ }^{32,33}$. Interestingly, interactions between B7-H1 and B7-1 have also been described ${ }^{34,35}$. These studies have indicated that the B7-H1-B7-1 interaction site and the B7-H1-PD1 interaction site are distinct but with some overlapping residues (FIG. 1d). Meanwhile, it seems that B7-H1, CD28 and CTLA4 may all interact with an overlapping site on B7-1 (REFS 32-35). Together these analyses suggest that competitive binding and exclusion mechanisms may operate among these molecules. The identification of novel interactions between co-signalling molecules and their structural determinants may reveal in the future that multiple interactions through multiple interfaces are common in co-signalling.

\section{Bi-directional co-signalling}

When two co-signalling molecules interact, intracellular signals may be transduced through both molecules; this is termed bi-directional co-signalling. Bi-directional co-signalling interactions have been well documented for TNFSF receptor-ligand interactions, as well as for homotypic interactions of SLAM family members (reviewed in REFS 13,36). Bidirectional interactions have also been described for members of the CD28-B7 family (FIG. 1). For example, engagement of B7-1 and B7-2 on dendritic cells by CTLA4 induces 
expression of indoleamine 2,3-dioxygenase (IDO), which then acts in trans to inhibit $\mathrm{T}$ cell function through tryptophan deprivation ${ }^{37}$. In addition, B7-1 expressed on T cells can transduce an inhibitory signal into T cells following its ligation by B7-H1 (REFS 34,35). Conversely, B7-H1 expressed on T cells can transduce an inhibitory signal into T cells after interaction with B7-1 (REF. 34). It remains to be clarified whether B7-1-B7-H1 interactions occur in vivo during $\mathrm{T}$ cell-T cell interactions or $\mathrm{T}$ cell interactions with other cells such as APCs. Bi-directional co-signalling can also occur through B7-H1-PD1 interactions. PD1 typically transduces inhibitory signals into T cells following interaction with B7-H1, but B7$\mathrm{H} 1$ expressed on cancer cells can also receive an anti-apoptotic signal from PD1 expressed on T cells ${ }^{38,39}$. However, whether PD1 can deliver signals through B7-H1 expressed on T cells remains unknown.

We recently identified PD1 homologue (PD1H; also known as VISTA), which potentially acts as a co-inhibitory receptor when expressed on T cells (REFS 40,41 and unpublished observations by D.B.F and L.C.). Moreover, it was shown that when expressed on APCs, $\mathrm{PD} 1 \mathrm{H}$ functions as an inhibitory ligand that suppresses $\mathrm{T}$ cells through an unidentified $\mathrm{T}$ cell counter-receptor ${ }^{41}$. Therefore, although the PD1H counter-receptor has yet to be identified, current data suggest that this molecular interaction is also bi-directional. As additional bidirectional co-signalling pairs may be identified in the future, traditional nomenclature defining the molecules that are engaged in co-signalling interactions as 'receptors' or 'ligands' may be misleading. Therefore, we suggest the use of the term 'counter-receptor'.

\section{Molecular pathway of $T$ cell co-signalling}

The signalling pathways activated downstream of the TCR and co-signalling receptors often overlap significantly. Therefore, although much has been discovered regarding pathways downstream of $\mathrm{T}$ cell co-stimulation and co-inhibition, it remains challenging to characterize the signalling events that underlie the unique functions of each co-stimulatory and coinhibitory receptor.

\section{CD28 and ICOS co-stimulatory signalling}

The intracellular domain structure of co-stimulatory receptors determines, at least in part, their functional outcomes. As a classic example, CD28 mediates a myriad of functions through two motifs in its cytoplasmic tail: YMNM and PYAP ${ }^{42}$. The proximal YMNM motif associates with the p85 subunit of phosphatidylinositol 3-kinase (PI3K), a common signalling intermediate, to initiate targeting of AKT (also known as protein kinase B (PKB)) that subsequently results in activation of several distal molecules ${ }^{42}$ (FIG. 2). The CD28PI3K-AKT pathway promotes $\mathrm{T}$ cell proliferation and survival through the activation of the downstream targets nuclear factor-KB (NF-KB), nuclear factor of activated T cells (NFAT), BCL-XL, mammalian target of rapamycin (mTOR), glucose transporter type 1 (GLUT1) and others (reviewed in REF. 42). In addition, both the YMNM and PYAP motifs are critically involved in the recruitment of protein kinase $\mathrm{C} \theta(\mathrm{PKC} \theta)$ to the immunological synapse and its subsequent activation (BOX 2). Interestingly, it has recently been shown that CD28 also recruits the RAS guanine nucleotide exchange factor (GEF) RAS guanyl nucleotide-releasing protein (RASGRP) to the T cell-APC interface to induce activation of RAS and the downstream phosphorylation of AKT, c-Jun N-terminal kinases (JNKs) and extracellular signal-regulated kinases (ERKs) ${ }^{43}$. The recruitment and activation of RASGRP seems to depend on the binding of the adaptor protein growth factor receptor-bound protein 2 (GRB2) to both the YMNM and PYAP motifs of CD28, and the recruitment of GRB2 may be the predominant signalling mechanism for interleukin-2 (IL-2) production in CD28 costimulated $\mathrm{T}$ cells ${ }^{43}$. In addition, the distal proline motif PYAP associates with lymphocyte cell-specific protein-tyrosine kinase (LCK) and GRB2 to enhance IL-2 induction by promoting the nuclear translocation of NFAT ${ }^{42}$. GRB2 is also crucial for phosphorylation of 
PKC $\theta$ and activation of JNKs, ERK1 and ERK2, whereas LCK promotes PKC $\theta$ activation through 3-phosphoinositide-dependent kinase 1 (PDK1) ${ }^{42}$.

ICOS contains a unique YMFM SH2 binding motif that recruits both $\mathrm{p} 85$ and p50a subunits of PI3K ${ }^{44}$. p50a is more active than p85, so its recruitment by ICOS results in enhanced AKT signalling compared with CD28 (REF. 44) (FIG. 2). ICOS signalling through PI3K and the resulting induction of IL-4, IL-10 and IL-21 expression are thought to be crucial for ICOS-mediated development of CD4 $4^{+} \mathrm{T}$ helper 2 cells $\left(\mathrm{T}_{\mathrm{H}} 2\right.$ cells) and $\mathrm{T}$ follicular helper cells $\left(\mathrm{T}_{\mathrm{FH}} \text { cells }\right)^{44}$. However, ICOS fails to bind GRB2 and LCK owing to the absence of a PYAP motif and thus cannot induce IL-2 production to the same extent as CD28 (REF. 45) . Moreover, unlike the YMNM motif of CD28, the YMFM motif of ICOS is unable to bind GRB2, suggesting that IL-2 production by T cells in response to co-stimulation largely depends on the recruitment of GRB2, as shown in the case of CD28 (REFS 43,45).

ICOS engages the C-MAF pathway to induce secretion of IL-4 and IL-21 (REFS 44-46). Moreover, it was recently shown that ICOS signalling is crucial for the induction of the transcriptional repressor BCL-6, which subsequently induced expression of CXC-chemokine receptor 5 (CXCR5), a defining molecule of $\mathrm{T}_{\mathrm{FH}}$ cells ${ }^{47}$. Most interestingly, a recent study indicated that C-MAF and BCL-6 cooperate to promote the $\mathrm{T}_{\mathrm{FH}}$ phenotype ${ }^{46}$. However, the exact role of ICOS signalling in the C-MAF and BCL-6 pathways requires further study. Comparison of the signalling events downstream of CD28 and ICOS has shown that costimulatory receptors recruit multiple proximal signalling molecules to activate several distal pathways, often through multiple routes. In turn, some distal signalling molecules, such as AKT, can activate more transcription factors than other distal molecules. This suggests a quantifiable level of influence for a specific signalling molecule based on potential nodes of interaction or, in other words, based on the versatility of the signalling molecule. Therefore, the function of co-stimulatory receptors seems to depend not only on the spectrum of the recruited proximal signalling molecules but also on the versatility of activated distal signalling pathways.

\section{IgSF co-inhibitory signalling: shared and unique mechanisms}

IgSF co-inhibitory receptors use several mechanisms to inhibit $\mathrm{T}$ cell function. Studies in mice expressing a CTLA4 mutant lacking the cytoplasmic region, and in particular the YVKM motif, demonstrate that this motif is important for CTLA4-mediated modulation of T cell function ${ }^{48}$. The YVKM motif associates with $\mathrm{SH} 2$ domain-containing tyrosine phosphatase 2 (SHP2; also known as PTPN11) and serine/threonine protein phosphatase 2A (PP2A), which reduce proximal TCR signalling through dephosphorylation of the TCR$\mathrm{CD} 3 \zeta$ complex, of linker for activation of T cells (LAT) and of $70 \mathrm{kDa}$ zeta-chain associated protein (ZAP70), thereby inhibiting cell cycle progression and cytokine production ${ }^{48}$ (FIG. 2). Additionally, CTLA4 ligation was found to regulate distal signalling events by inhibiting ERK and JNK phosphorylation ${ }^{48}$. Interestingly, the YVKM motif also binds PI3K, and it has recently been demonstrated that CTLA4 promotes $\mathrm{CD}^{+} \mathrm{T}$ cell migration through PI3Kdependent AKT activation ${ }^{49}$. Meanwhile, it remains unclear whether the CTLA4-PI3KAKT pathway also has a co-stimulatory function.

Unlike CTLA4, which shares the SH2-binding motif (YXXM) with CD28 and ICOS, the cytoplasmic tail of PD1 contains an immunoreceptor tyrosine-based inhibition motif (ITIM) and an immunoreceptor tyrosine-based switch motif $(\text { ITSM })^{50}$. Although both motifs appear to be phosphorylated following interaction with B7-H1 or B7-DC, recent evidence indicates that the ITSM motif recruits SHP2, and possibly SHP1 (also known as PTPN6), whereas the role of the ITIM motif remains unclear ${ }^{50,51}$. Similarly to CTLA4, studies show that translocation of PD1 to the central supra-molecular activation complex (cSMAC) of the immunological synapse (BOX 2) and its colocalization with TCR microclusters is required 
to induce dephosphorylation of CD3ろ, ZAP70 and PKC $\theta$ and the subsequent blockade of TCR-induced stop signals, which reduce $\mathrm{T}$ cell motility following encounter of a cognate antigen on an $\mathrm{APC}^{51-53}$ (FIG. 2). Recently it was found that PD1 may also inhibit RAS and, subsequently, its downstream targets ERK1 and ERK2 through an SHP1- and SHP2independent mechanism to inhibit cell cycling 54 .

The BTLA cytoplasmic tail resembles that of PD1 rather than that of CTLA4, given the arrangement of two tyrosine-containing immunoreceptor motifs capable of recruiting SHP1 and SHP2 (REF. 55). However, BTLA also resembles CD28 in that it contains a third tyrosine motif that can interact directly with GRB2 and indirectly - following the recruitment of GRB2 - with PI $3 \mathrm{~K}^{56}$. Mechanisms of inhibition, and potentially activation, by BTLA remain to be clarified.

Interestingly, recent studies have shown that the SLAM family receptors LY108 and 2B4 can induce both stimulatory and inhibitory signalling pathways in T cells (and natural killer (NK) cells) through the recruitment of the shared adaptor protein signalling lymphocytic activation molecule-associated protein (SAP) ${ }^{15,16,57}$. LY108, 2B4 and other SLAM receptors contain an ITSM motif in their cytoplasmic tail that binds to SAP family members after ITSM phosphorylation ${ }^{13}$. SAP contains an $\mathrm{SH} 2$ domain that was previously shown to indirectly promote $\mathrm{T}$ cell activation by blocking the phosphatases SHP1, SHP2 and SH2 domain-containing inositol phosphatase 1 (SHIP1; also known as phosphatidylinositol 3,4,5trisphosphate 5 -phosphatase 1$)^{13}$. However, SAP can also directly induce positive signalling by binding to PKC $\theta$ and $\mathrm{FYN}^{58,59}$. Recent studies have indicated that in the absence of SAP, LY108 recruits SHP1, whereas 2B4 recruits both SHP1 and SHIP1 to the immunological synapse to inhibit $\mathrm{T}$ cell (and NK cell) function ${ }^{15,16,57}$. Therefore, these studies provide evidence that an individual receptor can function as either a co-stimulatory or a co-inhibitory receptor depending on the induction of specific intracellular signalling mechanisms.

Finally, a recent study uncovered a novel mechanism of signalling regulation for the coinhibitory receptor TIM3 (REF. 60). In this study it was shown that human leukocyte antigen B-associated transcript 3 (BAT3; also known as BAG6) binds to the cytoplasmic tail of TIM3 in the absence of the TIM3 ligand galectin 9 to repress the inhibitory function of TIM3 in T cells. Although ligand binding is still required to inhibit T cell activity, repression of co-inhibitory signalling through cytoplasmic interactions provides an additional mechanism through which co-inhibitory molecules may be regulated.

Together, these studies indicate that co-inhibitory receptors use related yet distinct signalling pathways to regulate $\mathrm{T}$ cells. As novel mechanisms of regulation continue to be identified, it seems that co-inhibitory receptors have no single unifying feature. Therefore, we speculate that co-inhibitory receptors may have evolved independently to regulate distinct $\mathrm{T}$ cell functions.

\section{Co-stimulatory signalling downstream of TNFRSF receptors}

Receptors of the TNFRSF, including 4-1BB, OX40, CD27, CD30, DR3, GITR and HVEM, synergize with TCR-CD3 signalling to promote cell cycle progression, cytokine production and $\mathrm{T}$ cell survival ${ }^{61}$. Following upregulation on activated T cells, three TNF receptor monomers interact with trimerized ligands on APCs to form trimeric ligand-receptor complexes that configure and cluster receptor cytoplasmic tails to facilitate recruitment of TNF receptor-associated factor (TRAF) adaptor proteins ${ }^{10}$. TRAFs activate several distal signalling molecules, including canonical and non-canonical NF-KB, JNK, p38 mitogenactivated protein kinase (MAPK), activator protein 1 (AP1), ERK and NFAT, but how each specific TRAF adaptor links TNFRSF receptor functions with downstream pathways remains unclear ${ }^{61}$ (FIG. 3). 
4-1BB can bind TRAF1, TRAF2 and TRAF3 (the latter only in humans), OX40 and CD27 can bind TRAF2, TRAF3 and TRAF5, and HVEM and CD30 can bind TRAF1, TRAF2, TRAF3 and TRAF5, whereas GITR recruits only TRAF2 (REFS 62-64) (FIG. 3). Costimulation through $4-1 \mathrm{BB}, \mathrm{OX} 40$ and $\mathrm{CD} 27$ promotes $\mathrm{T}$ cell survival by upregulating antiapoptotic factors, including BCL-2, BCL-XL and BFL1 (also known as BCL2A1) ${ }^{61}$. In addition, co-stimulation through 4-1BB and OX40 activates AKT to promote cell cycling through regulation of cyclins and cyclin-dependent kinases ${ }^{61}$. OX40 was also recently shown to upregulate expression of TRAF6, leading to activation of non-canonical NF-KB signalling and induction of IL-9 production in $\mathrm{CD} 4^{+} \mathrm{T}$ cells, although the capacity of OX40 to bind TRAF6 is unclear ${ }^{65}$. Meanwhile, CD30 has been shown to have pleiotropic effects on $\mathrm{T}$ cell activation, apoptosis and effector function, although the signalling mechanisms mediating these effects remain unclear ${ }^{66}$. Interestingly, although HVEM binds the same set of TRAFs as CD30, HVEM signalling in T cells predominantly induces $\mathrm{T}_{\mathrm{H}} 1$ cell-associated cytokines $^{67}$. Additionally, HVEM has also recently been shown to induce additional signalling pathways including the NF-KB-dependent activation of signal transducer and activator of transcription 3 (STAT3) activation in T cells, as well as nitric oxide and hypoxia inducible factor $1 \mathrm{a}(\mathrm{HIF} 1 \mathrm{\alpha})$ in cell types other than $\mathrm{T}$ cells ${ }^{68,69}$.

Some TNFRSF co-signalling molecules recruit other adaptor molecules in addition to TRAFs. For example, DR3 uses an N-terminal TNFR-associated death domain (TRADD) adaptor protein to recruit a complex of TRAF2 with receptor-interacting protein 1 (RIP1; also known as RIPK1) that subsequently activates NF-KB and MAPK signalling pathways ${ }^{70}$ (FIG. 3). Moreover, GITR and CD27 bind the apoptosis-inducing factor SIVA1, a molecule with a death domain homology region that modulates BCL-2 family molecules and caspase activation $^{64,71}$ (FIG. 3). As GITR and CD27 function predominantly as co-stimulatory receptors and actually promote $\mathrm{T}$ cell survival, the outcome of SIVA1 binding remains to be clarified $^{64,71}$.

Notably, although each of the TNFRSF co-signalling receptors utilizes TRAF adaptors, the variability of known functions cannot be fully explained solely in association with these diverse TRAF adaptors, suggesting that distinct signalling mechanisms downstream of TNFRSF co-stimulatory molecules may be elucidated in the future. Moreover, although the proximal signalling molecules used by TNFRSF receptors are distinct from those recruited by TCR-CD3, CD28 and ICOS, the distal pathways are partially overlapping. This highlights the importance of these pathways for $\mathrm{T}$ cell function but also poses the question of how individual co-signalling receptors induce unique function in $\mathrm{T}$ cells despite the fact that many of the signalling pathways downstream of these receptors are shared.

\section{Co-signalling in $\mathrm{T}$ cell subsets}

The integration of signals downstream of the TCR and co-signalling receptors directs function in all phases of $\mathrm{T}$ cell responses, but we still understand little about how the repertoire of co-signalling receptors expressed on the $\mathrm{T}$ cell truly integrate into fate decision. TABLE 1 lists co-signalling receptors that induce positive and negative effects in $\mathrm{T}$ cells at specific phases of the $\mathrm{T}$ cell response, either through guiding activation and differentiation or through regulating effector function and survival. Here we describe the functions of cosignalling receptors during specific phases of $\mathrm{T}$ cell responses.

\section{Priming of naive T cells}

The events initiating the transition of conventional naive $\mathrm{T}$ cells from a quiescent to an activated state are referred to as $\mathrm{T}$ cell priming. A limited number of co-stimulatory receptors are expressed on naive T cells and can synergize with TCR-CD3 signalling to initiate priming, suggesting that this early phase is tightly regulated. CD28 seems to be the 
primary costimulatory molecule required for naive $\mathrm{T}$ cell priming, but other receptors may compensate to some extent in the absence of CD28 (REF. 72). CD2 can prime naive T cells in a ZAP70-dependent manner, thus resembling TCR-CD3 signalling, and has been found to induce signalling in the absence of both TCR and CD28 signalling ${ }^{73,74}$.

HVEM can also promote T cell priming following engagement of LIGHT ${ }^{22}$. However, as mentioned previously the window of opportunity for HVEM mediated co-stimulation in vivo is narrow; LIGHT is often cleaved or downregulated on activated APCs, whereas HVEM is downregulated following T cell activation ${ }^{22}$. LIGHT also functions as a costimulatory receptor when expressed on T cells ${ }^{22}$. Whether HVEM-LIGHT can substitute for the co-stimulatory function of CD28 has yet to be addressed.

In addition, $\mathrm{CD} 27$ is constitutively expressed on naive $\mathrm{T}$ cells and can promote $\mathrm{T}$ cell proliferation, although CD27 seems unable to initiate cell cycling in the absence of CD28 co-stimulation ${ }^{75}$. Forced expression of ICOS in sanroque mice on a CD28-deficient background demonstrates that ICOS can also compensate for some functions of CD28 when expressed on naive T cells ${ }^{76}$. However, ICOS is not expressed on naive T cells in physiological settings, and this indicates the importance of the tightly regulated expression patterns in $\mathrm{T}$ cell function.

\section{$\mathrm{CD4}^{+} \mathrm{T}$ helper cell differentiation and function}

Although many co-stimulatory and co-inhibitory receptors are upregulated following $\mathrm{T}$ cell priming, relatively few have defined functions in $\mathrm{CD}^{+} \mathrm{T}$ cell differentiation or $\mathrm{CD} 4^{+} \mathrm{T}_{\mathrm{H}}$ cell subset function (TABLE 1).

In activated $\mathrm{CD}^{+}{ }^{+} \mathrm{T}$ cells, SLAM family molecules largely promote polarization towards IL-4 production and inhibition of interferon- $Y\left(\right.$ IFNY) ${ }^{13}$. Moreover, TIM1 and TIM4 promote $\mathrm{T}_{\mathrm{H}} 2$ responses: TIM1 expression on $\mathrm{T}_{\mathrm{H}} 2$ cells enhances $\mathrm{T}_{\mathrm{H}} 2$ proliferation and IL-4 production ${ }^{11}$, and TIM4 expressed on APCs has been shown to bind TIM1 on T cells. However, TIM4 has also been shown to selectively inhibit $\mathrm{T}_{\mathrm{H}} 1$ and $\mathrm{T}_{\mathrm{H}} 17$ responses through an unidentified receptor other than TIM1 (REFS 77,78). Interestingly, TIM1, which can also be expressed on APCs, may interact with an unknown counter-receptor on $\mathrm{CD} 4^{+} \mathrm{T}$ cells to inhibit $\mathrm{T}_{\mathrm{H}} 1$ cell proliferation and function ${ }^{79}$. Further studies and counter-receptor identification will hopefully clarify and verify the role of TIM1 and TIM4 on CD4 ${ }^{+} \mathrm{T}$ cells.

ICOS was originally thought to preferentially promote $\mathrm{T}_{\mathrm{H}} 2$ proliferation and function (see also previous section). However, it now appears that ICOS also promotes the expansion and function of other $\mathrm{T}$ helper subsets $\left(\mathrm{T}_{\mathrm{H}} 1, \mathrm{~T}_{\mathrm{H}} 2, \mathrm{~T}_{\mathrm{H}} 17\right.$ and $\mathrm{T}_{\mathrm{FH}}$ cell subsets) and regulatory $\mathrm{T}$ $\left(\mathrm{T}_{\mathrm{Reg}}\right)$ cells in a context-dependent fashion ${ }^{44,46,47}$.

Finally, TNFRSF receptors can promote differentiation of activated $\mathrm{CD} 4^{+} \mathrm{T}$ cells into diverse $\mathrm{T}_{\mathrm{H}}$ subsets. CD27 and HVEM promote $\mathrm{T}_{\mathrm{H}} 1$ cell differentiation, whereas CD30 and DR3 preferentially promote the secretion of $\mathrm{T}_{\mathrm{H}} 2$ cell-associated cytokines $22,24,62,71,80$. Moreover, OX40 has now been shown to promote IL-9 secretion in CD4 $4^{+} \mathrm{T}$ cells ${ }^{65}$ (see also previous section).

As $\mathrm{CD} 4^{+} \mathrm{T}$ helper subset differentiation is a crucial phase for shaping the immune responses, it is likely that there are additional, as-yet-unidentified functions of co-signalling molecules in this process.

\section{$\mathbf{T}_{\text {Reg }}$ cells}

It is now clear that both co-stimulatory and co-inhibitory molecules are essential for the development and function of $\mathrm{CD} 4{ }^{+} \mathrm{CD} 25^{+} \mathrm{FOXP}^{+} \mathrm{T}_{\text {Reg }}$ cells ${ }^{81}$. Co-stimulation through 
CD28 is required for both the generation of $\mathrm{CD} 4^{+} \mathrm{CD} 25^{+} \mathrm{FOXP} 3^{+} \mathrm{T}_{\mathrm{Reg}}$ cells in the thymus (natural $\mathrm{T}_{\mathrm{Reg}}$ cells) and their maintenance in the periphery ${ }^{81}$. Although ICOS has not been found to be involved in the generation of natural $\mathrm{T}_{\mathrm{Reg}}$ cells, it promotes their proliferation, survival and maintenance ${ }^{44}$. TNFRSF co-stimulatory signals through HVEM, GITR and CD30 promote the suppressive capacity of $\mathrm{T}_{\text {Reg }}$ cells, whereas 4-1BB, OX40 and DR3 reduce $\mathrm{T}_{\text {Reg }}$ cell suppressive capacity but promote $\mathrm{T}_{\mathrm{Reg}}$ cell expansion ${ }^{22,63,71,80,82,83}$. The co-signalling receptors CTLA4, HVEM, LAG3 and PD1 are all expressed on $\mathrm{T}_{\text {Reg }}$ cells and may function in a cell-extrinsic manner to regulate conventional $\mathrm{T}$ cells through $\mathrm{T}$ cellconventional $\mathrm{T}_{\text {Reg }}$ cell interactions ${ }^{19,22,81,84}$ (FIG. 1c). For example, HVEM expressed on $\mathrm{T}_{\text {Reg }}$ cells functions as a ligand of BTLA on conventional T cells, and HVEM-BTLA interactions between $\mathrm{T}_{\mathrm{Reg}}$ cells and conventional $\mathrm{T}$ cells inhibit the latter ${ }^{85}$. Moreover, CTLA4 expressed on $\mathrm{T}_{\text {Reg }}$ cells interacts with B7-1 and B7-2 expressed on APCs to deliver reverse signals into APCs, which induce the expression of IDO ${ }^{37}$. IDO can subsequently activate $\mathrm{T}_{\text {Reg }}$ cells in the local microenvironment ${ }^{86}$ (FIG. 1b). In addition, CTLA4 on $\mathrm{T}_{\text {Reg }}$ cells may inhibit conventional $\mathrm{T}$ cells by delivering a suppressive signal through $\mathrm{B} 7-1$ expressed on target $\mathrm{T}$ cells ${ }^{87,88}$ (FIG. 1c). The finding that B7-H1 can bind to B7-1 suggests that the B7-H1-B7-1 interactions may also be involved in $\mathrm{T}_{\text {Reg }}$ cell function ${ }^{34,35,89}$. Interestingly, B7-H1 binding to PD1 on natural $\mathrm{T}_{\text {Reg }}$ cells has been shown to inhibit $\mathrm{T}_{\text {Reg }}$ cell suppressive function, whereas PD1 ligation on conventional $\mathrm{T}$ cells has been shown to promote their differentiation into induced $\mathrm{T}_{\mathrm{Reg}}$ cells ${ }^{90-93}$. Conversely, the ability of PD1 to deliver signals through $\mathrm{B} 7-\mathrm{H} 1$ on $\mathrm{T}_{\mathrm{Reg}}$ cells remains unclear. In many cases, the exact function of co-stimulatory and co-inhibitory molecules on both thymus-derived natural $\mathrm{T}_{\mathrm{Reg}}$ cells and peripherally induced $\mathrm{T}_{\text {Reg }}$ cells awaits further clarification.

\section{Effector T cells}

Co-signalling receptors, and particularly TNFRSF co-stimulatory receptors, have a substantial role in regulating effector T cell responses (TABLE 1). CD27-, OX40- and DR3mediated co-stimulation promotes proliferation and survival of both $\mathrm{CD}^{+}$and $\mathrm{CD} 8^{+}$ effector $\mathrm{T}$ cells, whereas 4-1BB- and GITR-mediated co-stimulation preferentially enhances the expansion and survival of $\mathrm{CD} 8^{+}$effector $\mathrm{T}$ cells ${ }^{61,63,64}$. HVEM is downregulated following $\mathrm{T}$ cell activation but is later upregulated on $\mathrm{CD} 4^{+}$and $\mathrm{CD} 8^{+}$effector $\mathrm{T}$ cells and promotes effector $\mathrm{T}$ cell function ${ }^{22}$. HVEM expressed on APCs can also promote effector $\mathrm{T}$ cell function through ligation of LIGHT on T cells ${ }^{22}$. Interestingly, whereas HVEM expression and signalling has a co-stimulatory function in effector T cells, HVEM expressed on APCs, effector T cells and $\mathrm{T}_{\text {Reg }}$ cells interacts with the co-inhibitory receptors BTLA and CD160, which are both upregulated on activated and effector T cells, thereby inhibiting target $\mathrm{T}$ cell function ${ }^{22}$. In fact, this inhibitory activity of HVEM through BTLA and CD160 signalling seems to be dominant in effector T cells, as expression of LIGHT, the only ligand capable of activating HVEM, is decreased in effector T cells and activated APCs, thus limiting potential positive signalling through HVEM on effector T cells ${ }^{28}$.

In addition to BTLA and CD160, many co-inhibitory receptors, including CTLA4, PD1, LAG3 and TIM3, are expressed during the effector T cell phase and limit both $\mathrm{CD}_{4}^{+}$and $\mathrm{CD}^{+}$effector T cell responses ${ }^{11,38,84,94}$ (TABLE 1; FIG. 1b). Although it is likely that the overall balance of co-stimulatory and co-inhibitory signalling in effector $\mathrm{T}$ cells qualitatively and quantitatively determines the effector $\mathrm{T}$ cell response, and subsequently the size and quality of the memory $\mathrm{T}$ cell pool, further studies are required to determine how concordant and conflicting signalling pathways integrate to achieve this regulation. Interestingly, the same co-inhibitory molecules that regulate effector $\mathrm{T}$ cell responses are also associated with induction of anergic and exhausted T cells, as discussed below, so it has yet to be clarified how co-inhibitory receptors regulate effector $\mathrm{T}$ cell inhibition versus the progression to $\mathrm{T}$ cell exhaustion. It is tempting to speculate that the functional outcome of co-inhibition may 
depend on the level (high versus low) and duration (acute versus chronic) of antigen exposure.

\section{Memory T cells}

Despite early studies suggesting that CD28 is not important for memory T cell responses, it was later confirmed that $\mathrm{CD} 28$ does have a role in memory $\mathrm{T}$ cell survival, as well as in secondary responses of $\mathrm{CD}^{+}$and $\mathrm{CD} 8^{+}$memory $\mathrm{T}$ cells to viral infections (reviewed in REF. 95). Similarly, ICOS deficiency results in a reduced memory $\mathrm{T}$ cell compartment and in defective memory $\mathrm{T}$ cell reactivation ${ }^{44}$. TNFRSF receptors are also crucial for memory $\mathrm{T}$ cell responses. For example, 4-1BB, OX40 and CD27 have all been shown individually to promote memory $\mathrm{T}$ cell responses, and can also act synergistically to determine the size and quality of the memory $\mathrm{CD} 8^{+} \mathrm{T}$ cell pool as well as to initiate memory $\mathrm{CD} 8^{+} \mathrm{T}$ cell expansion in response to secondary challenge ${ }^{96}$.

Uniquely, engagement of co-stimulatory receptors on memory $\mathrm{T}$ cells has been shown in some cases to stimulate memory T cells in the absence of TCR stimulation. For example, costimulation of $\mathrm{CD}^{+}$memory $\mathrm{T}$ cells with a 4-1BB agonist antibody induces proliferation and cytokine production in the absence of TCR stimulation ${ }^{97}$. Similar effects have been observed in $\mathrm{CD}^{+} \mathrm{T}$ cells following co-stimulation with OX40- or CD30-specific agonist monoclonal antibodies ${ }^{98,99}$. Notably, whereas superagonist monoclonal antibodies against CD28 have been shown to activate naive T cells independently of TCR signalling, agonist monoclonal antibodies targeting 4-1BB, OX40 and CD30 have little or no effect on naive T cell activation, suggesting that these monoclonal antibodies are not superagonists but induce TCR independent signalling pathways only in previously activated T cells ${ }^{100}$. The study of TCR-independent co-signalling in memory $\mathrm{T}$ cells may provide a unique opportunity for delineating signalling pathways that are specifically activated downstream of either TCR or co-stimulatory receptors.

\section{$T$ cell exhaustion and $T$ cell tolerance}

$\mathrm{T}$ cells chronically exposed to antigen, particularly during chronic viral infections or within tumour microenvironments, may develop an altered phenotype marked by a greatly reduced proliferative capacity and effector function, and by the upregulation of multiple coinhibitory molecules ${ }^{101}$. These $\mathrm{T}$ cells have been termed 'exhausted' $\mathrm{T}$ cells owing to their reduced response to ongoing stimuli. $\mathrm{T}$ cell exhaustion was first described for $\mathrm{CD} 8^{+} \mathrm{T}$ cells, and most studies to date have focused specifically on $\mathrm{CD} 8^{+} \mathrm{T}$ cells, but it is now apparent that $\mathrm{CD} 4^{+} \mathrm{T}$ cells can also develop an exhausted phenotype $\mathrm{e}^{60,101,102}$.

The most well-defined characteristic of exhausted $\mathrm{T}$ cells is their expression of multiple coinhibitory receptors, which in turn highly correlates with their degree of unresponsiveness ${ }^{101}$. Co-inhibitory molecules associated with exhausted $\mathrm{T}$ cells include PD1, TIM3, CTLA4, BTLA, CD160, LAG3 and 2B4 (REFS 101,103). Initial studies indicated that B7-H1-PD1 was a crucial pathway in the regulation of $\mathrm{CD}^{+} \mathrm{T}$ cell exhaustion, as blockade of B7-H1-PD1 interactions following chronic infection or in the tumour microenvironment restored $\mathrm{CD} 8^{+}$effector function, whereas blockade of other individual co-inhibitory pathways alone in these models of exhaustion showed less effect in rescuing T cells ${ }^{101,103}$. However, combined blockade of PD1-B7-H1 with other coinhibitors, most notably TIM3, CTLA4 and LAG3, has a synergistic effect in reversing exhaustion ${ }^{101,104,105}$. Interestingly, $\mathrm{T}$ cell exhaustion can be rescued through co-stimulatory signals. It was recently shown that an agonist monoclonal antibody specific for 4-1BB in combination with IL-7 can restore the activity of dysfunctional CD8 ${ }^{+} \mathrm{T}$ cells in a TRAF1dependent manner in a model of chronic infection with lymphocytic choriomeningitis virus $(\mathrm{LCMV})^{106}$. 
In contrast to exhausted $\mathrm{T}$ cells, which may retain some functionality in vivo, tolerant or anergic T cells are thought to develop in the presence of sub-optimal TCR stimulation or TCR stimulation in conditions of subthreshold co-stimulation or high levels of co-inhibition and show complete unresponsiveness following antigenic stimulation ${ }^{107,108}$. Additionally, as opposed to anergic $\mathrm{T}$ cells, which are thought to develop during initial antigen exposure, exhausted $\mathrm{T}$ cells are thought to develop progressively from continued antigen exposure ${ }^{101}$. In reality, it seems that a fine line exists between $\mathrm{T}$ cell anergy (or peripheral tolerance) and $\mathrm{T}$ cell exhaustion, and $\mathrm{T}$ cell exhaustion may actually be a uniquely programmed state of $\mathrm{T}$ cell anergy that develops to limit extensive pathology in the presence of chronic antigen exposure, as occurs in viral infections and cancer ${ }^{109}$. For example, CTLA4 and PD1 are crucial for the maintenance of central and peripheral tolerance, respectively, and both molecules are also involved in the development and maintenance of exhausted T cells ${ }^{101,110}$. Indeed, although gene-expression profiling comparisons of exhausted and tolerant or anergic $\mathrm{T}$ cells has shown some distinctions, similarities also exist ${ }^{101}$. Moreover, most $\mathrm{T}$ cell exhaustion studies to date have focused on $\mathrm{CD} 8^{+} \mathrm{T}$ cells while classical $\mathrm{T}$ cell anergy studies have focused on $\mathrm{CD}_{4}^{+} \mathrm{T}$ cells, so it remains unclear how $\mathrm{T}$ cell anergy and $\mathrm{T}$ cell exhaustion compare in vivo.

Finally, exhausted $\mathrm{T}$ cells are thought to develop during the progression from effector $\mathrm{T}$ cells to memory $\mathrm{T}$ cells, so it has been proposed that exhaustion of $\mathrm{T}$ cells may prevent the terminal differentiation of effector $\mathrm{T}$ cells to memory cells ${ }^{111-113}$. This may explain why long-term immunity could not be generated or maintained in chronic LCMV-infected mice ${ }^{112}$. Recently, transcriptional network analyses have compared the differences between exhausted and memory $\mathrm{T}$ cells and have found significant aberrations in many pathways in exhausted $\mathrm{T}$ cells ${ }^{114}$. Therefore, the better characterization of peripheral $\mathrm{T}$ cell tolerance, memory and exhaustion and the specific conditions and mechanisms involved will be of importance.

Although peripheral $\mathrm{T}$ cell tolerance and $\mathrm{T}$ cell exhaustion are not yet fully understood, the apparent synergy of multiple co-inhibitory molecules and the competing forces of costimulatory signalling on exhausted $\mathrm{T}$ cells provides insight into the integration of costimulatory and co-inhibitory pathways. Therefore, the study of co-stimulatory and coinhibitory signalling in exhausted $\mathrm{T}$ cells and comparisons of co-signalling networks in tolerant or anergic, effector, memory and exhausted T cells may be a means to elucidate integrative co-signalling pathways.

\section{Perspectives}

Co-signalling molecules imbue in T cells a mechanism to sense external environmental conditions and respond accordingly. The designation of co-signalling molecules as simply co-stimulatory or co-inhibitory has evolved into something significantly more complex as new interactions and multi-level functionality continue to be discovered. As previously unappreciated co-signalling interactions continue to be identified and characterized, we now envision the simplicity of the classic two-signal model of co-stimulation being replaced by a more complex tidal model of co-signalling.

Although much has been discovered since the early 1990s, the field of co-signalling research remains in relative mechanistic infancy. Key issues remaining to be resolved include the regulation and control of co-stimulatory and co-inhibitory molecule expression, the elucidation of both known and novel co-stimulatory and co-inhibitory pathways, and how downstream co-signalling patterns integrate to direct specific processes of $\mathrm{T}$ cell growth, differentiation and survival. Enthusiasm in the field of co-signalling research has been fuelled by the success of co-stimulatory and co-inhibitory immunotherapy for the treatment 
of human diseases (BOX 3), but continued success depends upon progress in understanding the underlying mechanisms of co-signalling function in both health and disease.

\section{Supplementary Material}

Refer to Web version on PubMed Central for supplementary material.

\section{Acknowledgments}

The authors thank B. Cadugan for editing the manuscript. The work in the authors laboratory has been supported by US National Institutes of Health (NIH) grants CA142779, CA121974, CA97085, CA16359, CA86721, AI72592 and the Melanoma Research Alliance.

\section{Glossary}

\section{Two-signal model}

Immunological synapse

Trans-endocytosis

Affinity

Bi-directional cosignalling

Indoleamine 2,3dioxygenase

T follicular helper cells

TNF receptorassociated factor
Activation of naive $\mathrm{T}$ cells requires two signals: $\mathrm{T}$ cell receptor (TCR) signalling and co-stimulatory signalling. TCR signalling following interaction with peptide-MHC complexes confers specificity to $\mathrm{T}$ cell activation but results in $\mathrm{T}$ cell unresponsiveness in the absence of co-stimulatory signalling, which synergizes with TCR signalling.

A large junctional structure that is formed following the initial $\mathrm{T}$ cell receptor recognition of cognate peptide-MHC complexes on antigen-presenting cells. This structure, which is composed of central and peripheral supra-molecular activation clusters (SMACs), is crucial for the spatial organization of surface interactions, cytoplasmic signalling components and scaffolds.

A process whereby material from one cell, such as cell surface molecules and portions of the cell membrane, enters or is endocytosed by another cell. This process is often referred to as trogocytosis when cell surface components are physically transendocytosed following cellular interactions.

The strength of binding of one molecule to another molecule. It is represented by the dissociation constant $\left(K_{\mathrm{d}}\right)$, which is the concentration of one molecule required to occupy half of the binding sites of a second molecule.

When two interacting molecules on two different cells both function as receptors and transduce a signal into their respective cell.

(IDO). An intracellular haem-containing enzyme that catalyses the oxidative catabolism of tryptophan. Insufficient availability of tryptophan can lead to $\mathrm{T}$ cell apoptosis and anergy.

( $\mathrm{T}_{\mathrm{FH}}$ cells). Antigen-experienced $\mathrm{CD} 4^{+} \mathrm{T}$ cells expressing CXCchemokine receptor 5 (CXCR5) ${ }^{+}$and B cell lymphoma 6 (BCL6) ${ }^{+}$. $\mathrm{T}_{\mathrm{FH}}$ cells are found in the $\mathrm{B}$ cell follicles of secondary lymphoid organs, and they induce germinal centre formation and regulate germinal centre B cell activation and function.

(TRAF). A family of conserved adaptor proteins containing a Cterminal domain that interacts with tumour necrosis factor receptor superfamily and other cell surface receptors and an N-terminal domain that links receptors with downstream signalling events. 


\section{Non-canonical NF-KB signalling}

Sanroque mice
A pathway that requires the activation of the nuclear factor- $\mathrm{KB}$ (NF$\mathrm{KB}$ )-inducing kinase (NIK) to process the NF- $\mathrm{KB} 2$ precursor protein p100 into a mature p52 subunit, which then dimerizes with RelB (RelB-p52) to regulate a distinct pattern of gene expression compared to the canonical pathway, which relies on RelA-p50 dimers.

A mouse strain that carries a loss-of-function mutation in the gene roquin, a zinc finger transcription factor that represses inducible $\mathrm{T}$ cell co-stimulator (ICOS) mRNA. These mice therefore overexpress ICOS and have a T cell-mediated systemiclupus-erythematosus-like syndrome and severe autoimmune diabetes when on a susceptible genetic background.

\section{References}

1. June CH, Ledbetter JA, Gillespie MM, Lindsten T, Thompson CB. T-cell proliferation involving the CD28 pathway is associated with cyclosporine-resistant interleukin 2 gene expression. Mol. Cell. Biol. 1987; 7:4472-4481. [PubMed: 2830495] This paper identified CD28 as a co-stimulator that could amplify TCR signalling to induce proliferation and IL-2 production.

2. Bretscher P, Cohn M. A theory of self-nonself discrimination. Science. 1970; 169:1042-1049. [PubMed: 4194660] In this paper Bretscher and Cohn first proposed a model in which two signals would be required for cellular activation of B cells as a mechanism of self-non-self discrimination.

3. Mueller DL, Jenkins MK, Schwartz RH. Clonal expansion versus functional clonal inactivation: a costimulatory signalling pathway determines the outcome of $\mathrm{T}$ cell antigen receptor occupancy. Annu. Rev. Immunol. 1989; 7:445-480. [PubMed: 2653373] This paper showed that TCR signalling in the absence of additional signals was insufficient to activate $\mathrm{T}$ cells and rendered $\mathrm{T}$ cells unresponsive to subsequent stimulation.

4. Liechtenstein T, Dufait I, Lanna A, Breckpot K, Escors D. Modulating co-stimulation during antigen presentation to enhance cancer immunotherapy. Immunol. Endocr. Metab. Agents Med. Chem. 2012; 12:224-235. [PubMed: 22945252]

5. Saito T, Yokosuka T, Hashimoto-Tane A. Dynamic regulation of T cell activation and costimulation through TCR-microclusters. FEBS Lett. 2010; 584:4865-4871. [PubMed: 21110974]

6. Greenwald RJ, Freeman GJ, Sharpe AH. The B7 family revisited. Annu. Rev. Immunol. 2005; 23:515-548. [PubMed: 15771580]

7. Gonzalez LC, et al. A coreceptor interaction between the CD28 and TNF receptor family members B and T lymphocyte attenuator and herpesvirus entry mediator. Proc. Natl Acad. Sci. USA. 2005; 102:1116-1121. [PubMed: 15647361]

8. Sedy JR, et al. B and T lymphocyte attenuator regulates T cell activation through interaction with herpesvirus entry mediator. Nature Immunol. 2005; 6:90-98. [PubMed: 15568026]

9. Brandt CS, et al. The B7 family member B7-H6 is a tumor cell ligand for the activating natural killer cell receptor NKp30 in humans. J. Exp. Med. 2009; 206:1495-1503. [PubMed: 19528259]

10. Chattopadhyay K, et al. Sequence, structure, function, immunity: structural genomics of costimulation. Immunol. Rev. 2009; 229:356-386. [PubMed: 19426233]

11. Kane LP. T cell Ig and mucin domain proteins and immunity. J. Immunol. 2010; 184:2743-2749. [PubMed: 20200285]

12. Bierer BE, Peterson A, Gorga JC, Herrmann SH, Burakoff SJ. Synergistic T cell activation via the physiological ligands for CD2 and the T cell receptor. J. Exp. Med. 1988; 168:1145-1156. [PubMed: 2459290]

13. Cannons JL, Tangye SG, Schwartzberg PL. SLAM family receptors and SAP adaptors in immunity. Annu. Rev. Immunol. 2011; 29:665-705. [PubMed: 21219180] 
14. Bengsch B, et al. Coexpression of PD-1, 2B4, CD160 and KLRG1 on exhausted HCV-specific $\mathrm{CD}^{+} \mathrm{T}$ cells is linked to antigen recognition and T cell differentiation. PLoS Pathog. 2010; 6:e1000947. [PubMed: 20548953]

15. Kageyama R, et al. The receptor Ly108 functions as a SAP adaptor-dependent on-off switch for T cell help to B cells and NKT cell development. Immunity. 2012; 36:986-1002. [PubMed: 22683125]

16. Zhao F, Cannons JL, Dutta M, Griffiths GM, Schwartzberg PL. Positive and negative signaling through SLAM receptors regulate synapse organization and thresholds of cytolysis. Immunity. 2012; 36:1003-1016. [PubMed: 22683123]

17. Schwartzberg PL, Mueller KL, Qi H, Cannons JL. SLAM receptors and SAP influence lymphocyte interactions, development and function. Nature Rev. Immunol. 2009; 9:39-46. [PubMed: 19079134]

18. Arnett HA, Escobar SS, Viney JL. Regulation of costimulation in the era of butyrophilins. Cytokine. 2009; 46:370-375. [PubMed: 19380239]

19. Sierro S, Romero P, Speiser DE. The CD4-like molecule LAG-3, biology and therapeutic applications. Expert Opin. Ther. Targets. 2011; 15:91-101. [PubMed: 21142803]

20. Chan CJ, Andrews DM, Smyth MJ. Receptors that interact with nectin and nectin-like proteins in the immunosurveillance and immunotherapy of cancer. Curr. Opin. Immunol. 2012; 24:246-251. [PubMed: 22285893]

21. Meyaard L. LAIR and collagens in immune regulation. Immunol. Lett. 2010; 128:26-28. [PubMed: 19836418]

22. del Rio ML, Lucas CL, Buhler L, Rayat G, Rodriguez-Barbosa JI. HVEM/LIGHT/BTLA/CD160 cosignaling pathways as targets for immune regulation. J. Leukoc. Biol. 2010; 87:223-235. [PubMed: 20007250]

23. Magis C, van der Sloot AM, Serrano L, Notredame C. An improved understanding of TNFL/TNFR interactions using structure-based classifications. Trends Biochem. Sci. 2012; 37:353-363. [PubMed: 22789664]

24. Croft M, et al. TNF superfamily in inflammatory disease: translating basic insights. Trends Immunol. 2012; 33:144-152. [PubMed: 22169337]

25. Sica GL, et al. RELT, a new member of the tumor necrosis factor receptor superfamily, is selectively expressed in hematopoietic tissues and activates transcription factor NF-KB. Blood. 2001; 97:2702-2707. [PubMed: 11313261]

26. Qureshi OS, et al. Trans-endocytosis of CD80 and CD86: a molecular basis for the cell-extrinsic function of CTLA-4. Science. 2011; 332:600-603. [PubMed: 21474713]

27. Zhu Y, Yao S, Chen L. Cell surface signaling molecules in the control of immune responses: a tide model. Immunity. 2011; 34:466-478. [PubMed: 21511182]

28. Cai G, Freeman GJ. The CD160, BTLA, LIGHT/HVEM pathway: a bidirectional switch regulating T-cell activation. Immunol. Rev. 2009; 229:244-258. [PubMed: 19426226]

29. Yao S, et al. B7-H2 is a costimulatory ligand for CD28 in human. Immunity. 2011; 34:729-740. [PubMed: 21530327]

30. Yoshinaga SK, et al. T-cell co-stimulation through B7RP-1 and ICOS. Nature. 1999; 402:827-832. [PubMed: 10617205]

31. Wang S, et al. Costimulation of T cells by B7-H2, a B7-like molecule that binds ICOS. Blood. 2000; 96:2808, 2813. [PubMed: 11023515]

32. Lin DY, et al. The PD-1/PD-L1 complex resembles the antigen-binding Fv domains of antibodies and T cell receptors. Proc. Natl Acad. Sci. USA. 2008; 3011:3016.

33. Lazar-Molnar E, et al. Crystal structure of the complex between programmed death-1 (PD-1) and its ligand PD-L2. Proc. Natl Acad. Sci. USA. 2008; 105:10483-10488. [PubMed: 18641123]

34. Butte MJ, Keir ME, Phamduy TB, Sharpe AH, Freeman GJ. Programmed death-1 ligand 1 interacts specifically with the B7-1 costimulatory molecule to inhibit T cell responses. Immunity. 2007; 27:111-122. [PubMed: 17629517] This paper, along with reference 35 describes a functional interaction between B7-H1 and B7-1.

35. Park JJ, et al. B7-H1/CD80 interaction is required for the induction and maintenance of peripheral T cell tolerance. Blood. 2010; 116:1291-1298. [PubMed: 20472828] 
36. Eissner G, Kolch W, Scheurich P. Ligands working as receptors: reverse signaling by members of the TNF superfamily enhance the plasticity of the immune system. Cytokine Growth Factor Rev. 2004; 15:353-366. [PubMed: 15450251]

37. Munn DH, Sharma MD, Mellor AL. Ligation of B7-1/B7-2 by human CD4 ${ }^{+} \mathrm{T}$ cells triggers indoleamine 2,3-dioxygenase activity in dendritic cells. J. Immunol. 2004; 172:4100-4110. [PubMed: 15034022]

38. Keir ME, Butte MJ, Freeman GJ, Sharpe AH. PD-1 and its ligands in tolerance and immunity. Annu. Rev. Immunol. 2008; 26:677-704. [PubMed: 18173375]

39. Azuma T, et al. B7-H1 is a ubiquitous antiapoptotic receptor on cancer cells. Blood. 2008; 111:3635-3643. [PubMed: 18223165]

40. Flies DB, Wang S, Xu H, Chen L. Cutting edge: a monoclonal antibody specific for the programmed death-1 homolog prevents graft-versus-host disease in mouse models. J. Immunol. 2011; 187:1537-1541. [PubMed: 21768399]

41. Wang L, et al. VISTA, a novel mouse Ig superfamily ligand that negatively regulates $\mathrm{T}$ cell responses. J. Exp. Med. 2011; 208:577-592. [PubMed: 21383057]

42. Boomer JS, Green JM. An enigmatic tail of CD28 signaling. Cold Spring Harb. Perspect. Biol. 2010; 2:a002436. [PubMed: 20534709]

43. Janardhan SV, Praveen K, Marks R, Gajewski TF. Evidence implicating the Ras pathway in multiple CD28 costimulatory functions in $\mathrm{CD}^{+}{ }^{+}$T cells. PLoS ONE. 2011; 6:e24931. [PubMed: 21949793]

44. Simpson TR, Quezada SA, Allison JP. Regulation of CD4 T cell activation and effector function by inducible costimulator (ICOS). Curr. Opin. Immunol. 2010; 22:326-332. [PubMed: 20116985]

45. Rudd CE, Schneider H. Unifying concepts in CD28, ICOS and CTLA4 co-receptor signalling. Nature Rev. Immunol. 2003; 3:544-556. [PubMed: 12876557]

46. Kroenke MA, et al. Bcl6 and Maf cooperate to instruct human follicular helper CD4 T cell differentiation. J. Immunol. 2012; 188:3734-3744. [PubMed: 22427637]

47. Choi YS, et al. ICOS receptor instructs $\mathrm{T}$ follicular helper cell versus effector cell differentiation via induction of the transcriptional repressor Bcl6. Immunity. 2011; 34:932-946. [PubMed: 21636296]

48. Rudd CE, Taylor A, Schneider H. CD28 and CTLA-4 coreceptor expression and signal transduction. Immunol. Rev. 2009; 229:12-26. [PubMed: 19426212]

49. Knieke K, Lingel H, Chamaon K, Brunner-Weinzierl MC. Migration of Th1 lymphocytes is regulated by CD152 (CTLA-4)-mediated signaling via PI3 kinase-dependent Akt activation. PLoS ONE. 2012; 7:e31391. [PubMed: 22412835]

50. Riley JL. PD-1 signaling in primary T cells. Immunol. Rev. 2009; 229:114-125. [PubMed: 19426218]

51. Yokosuka T, et al. Programmed cell death 1 forms negative costimulatory microclusters that directly inhibit T cell receptor signaling by recruiting phosphatase SHP2. J. Exp. Med. 2012; 209:1201-1217. [PubMed: 22641383]

52. Yokosuka T, et al. Spatiotemporal basis of CTLA-4 costimulatory molecule-mediated negative regulation of T cell activation. Immunity. 2010; 33:326-339. [PubMed: 20870175]

53. Sheppard KA, et al. PD-1 inhibits T-cell receptor induced phosphorylation of the ZAP70/CD3Z signalosome and downstream signaling to PKC $\theta$. FEBS Lett. 2004; 574:37-41. [PubMed: 15358536]

54. Patsoukis N, et al. Selective effects of PD-1 on Akt and Ras pathways regulate molecular components of the cell cycle and inhibit T cell proliferation. Sci. Signal. 2012; 5:ra46. [PubMed: 22740686]

55. Gavrieli M, Watanabe N, Loftin SK, Murphy TL, Murphy KM. Characterization of phosphotyrosine binding motifs in the cytoplasmic domain of $\mathrm{B}$ and $\mathrm{T}$ lymphocyte attenuator required for association with protein tyrosine phosphatases SHP-1 and SHP-2. Biochem. Biophys. Res. Commun. 2003; 312:1236-1243. [PubMed: 14652006]

56. Gavrieli M, Murphy KM. Association of Grb-2 and PI3K p85 with phosphotyrosile peptides derived from BTLA. Biochem. Biophys. Res. Commun. 2006; 345:1440-1445. [PubMed: 16725108] 
57. Dong Z, et al. The adaptor SAP controls NK cell activation by regulating the enzymes Vav-1 and SHIP-1 and by enhancing conjugates with target cells. Immunity. 2012; 36:974-985. [PubMed: 22683124]

58. Cannons JL, et al. Biochemical and genetic evidence for a SAP-PKC- $\theta$ interaction contributing to IL-4 regulation. J. Immunol. 2010; 185:2819-2827. [PubMed: 20668219]

59. Bloch-Queyrat C, et al. Regulation of natural cytotoxicity by the adaptor SAP and the Src-related kinase Fyn. J. Exp. Med. 2005; 202:181-192. [PubMed: 15998796]

60. Rangachari M, et al. Bat3 promotes $\mathrm{T}$ cell responses and autoimmunity by repressing Tim-3mediated cell death and exhaustion. Nature Med. 2012; 18:1394-1400. [PubMed: 22863785]

61. Croft M. The role of TNF superfamily members in T-cell function and diseases. Nature Rev. Immunol. 2009; 9:271-285. [PubMed: 19319144]

62. Croft M. Co-stimulatory members of the TNFR family: keys to effective T-cell immunity? Nature Rev. Immunol. 2003; 3:609-620. [PubMed: 12974476]

63. Wang C, Lin GH, McPherson AJ, Watts TH. Immune regulation by 4-1BB and 4-1BBL: complexities and challenges. Immunol. Rev. 2009; 229:192-215. [PubMed: 19426223]

64. Nocentini G, Riccardi C. GITR: a modulator of immune response and inflammation. Adv. Exp. Med. Biol. 2009; 647:156-173. [PubMed: 19760073]

65. Xiao X, et al. OX40 signaling favors the induction of $\mathrm{T}_{\mathrm{H}} 9$ cells and airway inflammation. Nature Immunol. 2012; 13:981-990. [PubMed: 22842344]

66. Podack ER, Strbo N, Sotosec V, Muta H. CD30-governor of memory T cells? Ann. NY Acad. Sci. 2002; 975:101-113. [PubMed: 12538158]

67. Steinberg MW, Cheung TC, Ware CF. The signaling networks of the herpesvirus entry mediator (TNFRSF14) in immune regulation. Immunol. Rev. 2011; 244:169-187. [PubMed: 22017438]

68. Shui JW, et al. HVEM signalling at mucosal barriers provides host defence against pathogenic bacteria. Nature. 2012; 488:222-225. [PubMed: 22801499]

69. Sakoda Y, et al. Dichotomous regulation of GVHD through bidirectional functions of the BTLAHVEM pathway. Blood. 2011; 117:2506-2514. [PubMed: 21220749]

70. Pobezinskaya YL, Choksi S, Morgan MJ, Cao X, Liu ZG. The adaptor protein TRADD is essential for TNF-like ligand 1A/death receptor 3 signaling. J. Immunol. 2011; 186:5212-5216. [PubMed: 21421854]

71. Nolte MA, van Olffen RW, van Gisbergen KP, van Lier RA. Timing and tuning of CD27-CD70 interactions: the impact of signal strength in setting the balance between adaptive responses and immunopathology. Immunol. Rev. 2009; 229:216-231. [PubMed: 19426224]

72. Shahinian A, et al. Differential T cell costimulatory requirements in CD28-deficient mice. Science. 1993; 261:609-612. [PubMed: 7688139] This article showed that CD28 is essential for T cell activation but that in the absence of CD28, other signals can compensate to a limited extent to costimulate T cells.

73. Meinl E, et al. Differential requirement of ZAP-70 for CD2-mediated activation pathways of mature human T cells. J. Immunol. 2000; 165:3578-3583. [PubMed: 11034358]

74. Green JM, Karpitskiy V, Kimzey SL, Shaw AS. Coordinate regulation of T cell activation by CD2 and CD28. J. Immunol. 2000; 164:3591-3595. [PubMed: 10725714]

75. Denoeud J, Moser M. Role of CD27/CD70 pathway of activation in immunity and tolerance. J. Leukoc. Biol. 2011; 89:195-203. [PubMed: 20699361]

76. Linterman MA, et al. Roquin differentiates the specialized functions of duplicated T cell costimulatory receptor genes CD28 and ICOS. Immunity. 2009; 30:228-241. [PubMed: 19217324]

77. Mizui M, et al. Bimodal regulation of T cell-mediated immune responses by TIM-4. Int. Immunol. 2008; 20:695-708. [PubMed: 18367551]

78. Cao W, Ryan M, Buckley D, O'Connor R, Clarkson MR. Tim-4 inhibition of T-cell activation and $\mathrm{T}$ helper type 1 differentiation requires both the immunoglobulin $\mathrm{V}$ and mucin domains and occurs via the mitogen-activated protein kinase pathway. Immunology. 2011; 133:179-189. [PubMed: 21463297] 
79. Xiao L, et al. Suppression of allograft rejection by Tim-1-Fc through cross-linking with a novel Tim-1 binding partner on T cells. PLoS ONE. 2011; 6:e21697. [PubMed: 21750723]

80. Meylan F, Richard AC, Siegel RM. TL1A and DR3, a TNF family ligand-receptor pair that promotes lymphocyte costimulation, mucosal hyperplasia, and autoimmune inflammation. Immunol. Rev. 2011; 244:188-196. [PubMed: 22017439]

81. Bour-Jordan H, Bluestone JA. Regulating the regulators: costimulatory signals control the homeostasis and function of regulatory T cells. Immunol. Rev. 2009; 229:41-66. [PubMed: 19426214]

82. Xiao X, et al. New insights on OX40 in the control of T cell immunity and immune tolerance in vivo. J. Immunol. 2012; 188:892-901. [PubMed: 22147766]

83. Zeiser R, et al. Early CD30 signaling is critical for adoptively transferred CD $4{ }^{+} \mathrm{CD} 25^{+}$regulatory $\mathrm{T}$ cells in prevention of acute graft-versus-host disease. Blood. 2007; 109:2225-2233. [PubMed: 17068147]

84. Walker LS, Sansom DM. The emerging role of CTLA4 as a cell-extrinsic regulator of T cell responses. Nature Rev. Immunol. 2011; 11:852-863. [PubMed: 22116087]

85. Tao R, Wang L, Murphy KM, Fraser CC, Hancock WW. Regulatory T cell expression of herpesvirus entry mediator suppresses the function of B and T lymphocyte attenuator-positive effector T cells. J. Immunol. 2008; 180:6649-6655. [PubMed: 18453584]

86. Sharma MD, et al. Plasmacytoid dendritic cells from mouse tumor-draining lymph nodes directly activate mature Tregs via indoleamine 2,3-dioxygenase. J. Clin. Invest. 2007; 117:2570-2582. [PubMed: 17710230]

87. Taylor PA, et al. B7 expression on T cells down-regulates immune responses through CTLA-4 ligation via T-T interactions. J. Immunol. 2004; 172:34-39. [PubMed: 14688306]

88. Paust S, Lu L, McCarty N, Cantor H. Engagement of B7 on effector T cells by regulatory T cells prevents autoimmune disease. Proc. Natl Acad. Sci. USA. 2004; 101:10398-10403. [PubMed: 15235129]

89. Paterson AM, et al. The programmed death-1 ligand 1 B7-1 pathway restrains diabetogenic effector T cells in vivo. J. Immunol. 2011; 187:1097-1105. [PubMed: 21697456]

90. Amarnath $\mathrm{S}$, et al. The PDL1-PD1 axis converts human $\mathrm{T}_{\mathrm{H}} 1$ cells into regulatory $\mathrm{T}$ cells. Sci. Transl. Med. 2011; 3:111ra120.

91. Amarnath $\mathrm{S}$, et al. Regulatory T cells and human myeloid dendritic cells promote tolerance via programmed death ligand-1. PLoS Biol. 2010; 8:e1000302. [PubMed: 20126379]

92. Franceschini D, et al. PD-L1 negatively regulates $\mathrm{CD} 4^{+} \mathrm{CD} 25^{+} \mathrm{Foxp} 3^{+}$Tregs by limiting STAT-5 phosphorylation in patients chronically infected with HCV. J. Clin. Invest. 2009; 119:551-564. [PubMed: 19229109]

93. Francisco LM, et al. PD-L1 regulates the development, maintenance, and function of induced regulatory T cells. J. Exp. Med. 2009; 206:3015-3029. [PubMed: 20008522]

94. Baitsch L, et al. Extended co-expression of inhibitory receptors by human CD8 T-cells depending on differentiation, antigen-specificity and anatomical localization. PLoS ONE. 2012; 7:e30852. [PubMed: 22347406]

95. Boesteanu AC, Katsikis PD. Memory T cells need CD28 costimulation to remember. Semin. Immunol. 2009; 21:69-77. [PubMed: 19268606]

96. Hendriks J, et al. During viral infection of the respiratory tract, CD27, 4-1BB, and OX40 collectively determine formation of $\mathrm{CD}^{+}$memory $\mathrm{T}$ cells and their capacity for secondary expansion. J. Immunol. 2005; 175:1665-1676. [PubMed: 16034107]

97. Zhu Y, Zhu G, Luo L, Flies AS, Chen L. CD137 stimulation delivers an antigen-independent growth signal for T lymphocytes with memory phenotype. Blood. 2007; 109:4882-4889. [PubMed: 17244673]

98. Harlin H, Podack E, Boothby M, Alegre ML. TCR-independent CD30 signaling selectively induces IL-13 production via a TNF receptor-associated factor/p38 mitogen-activated protein kinase-dependent mechanism. J. Immunol. 2002; 169:2451-2459. [PubMed: 12193714]

99. Redmond WL, Ruby CE, Weinberg AD. The role of OX40-mediated co-stimulation in T-cell activation and survival. Crit. Rev. Immunol. 2009; 29:187-201. [PubMed: 19538134] 
100. Suntharalingam G, et al. Cytokine storm in a phase 1 trial of the anti-CD28 monoclonal antibody TGN1412. N. Engl. J. Med. 2006; 355:1018-1028. [PubMed: 16908486]

101. Wherry EJ. T cell exhaustion. Nature Immunol. 2011; 12:492-499. [PubMed: 21739672] This paper provides a detailed review of $\mathrm{T}$ cell exhaustion.

102. Antoine $\mathrm{P}$, et al. Functional exhaustion of $\mathrm{CD}^{+} \mathrm{T}$ lymphocytes during primary cytomegalovirus infection. J. Immunol. 2012; 189:2665-2672. [PubMed: 22865914]

103. Fourcade $\mathrm{J}$, et al. $\mathrm{CD}^{+} \mathrm{T}$ cells specific for tumor antigens can be rendered dysfunctional by the tumor microenvironment through upregulation of the inhibitory receptors BTLA and PD-1. Cancer Res. 2012; 72:887-896. [PubMed: 22205715]

104. Sakuishi K, Jayaraman P, Behar SM, Anderson AC, Kuchroo VK. Emerging Tim-3 functions in antimicrobial and tumor immunity. Trends Immunol. 2011; 32:345-349. [PubMed: 21697013]

105. Goldberg MV, Drake CG. LAG-3 in cancer immunotherapy. Curr. Top. Microbiol. Immunol. 2011; 344:269-278. [PubMed: 21086108]

106. Wang C, et al. Loss of the signaling adaptor TRAF1 causes CD8 ${ }^{+} \mathrm{T}$ cell dysregulation during human and murine chronic infection. J. Exp. Med. 2012; 209:77-91. [PubMed: 22184633] This paper was the first to show that $\mathrm{T}$ cell exhaustion can be reversed through co-stimulation.

107. Schwartz RH, Mueller DL, Jenkins MK, Quill H. T-cell clonal anergy. Cold Spring Harb. Symp. Quant. Biol. 1989; 54:605-610. [PubMed: 2534840] This was the first paper to use the term anergy to describe the functional unresponsive state induced in T cells in the presence of only TCR stimulation (signal one) in the absence of additional signals (signal two).

108. Schwartz RH. T cell anergy. Annu. Rev. Immunol. 2003; 21:305-334. [PubMed: 12471050]

109. McAfee MS, Blattman JN. Combating chronic T-cell exhaustion. Immunotherapy. 2012; 4:557560. [PubMed: 22788120]

110. Fife BT, Bluestone JA. Control of peripheral T-cell tolerance and autoimmunity via the CTLA-4 and PD-1 pathways. Immunol. Rev. 2008; 224:166-182. [PubMed: 18759926]

111. Takamura $S$, et al. Premature terminal exhaustion of friend virus-specific effector $\mathrm{CD} 8^{+} \mathrm{T}$ cells by rapid induction of multiple inhibitory receptors. J. Immunol. 2010; 184:4696-4707. [PubMed: 20351188]

112. Angelosanto JM, Blackburn SD, Crawford A, Wherry EJ. Progressive loss of memory T cell potential and commitment to exhaustion during chronic viral infection. J. Virol. 2012; 86:81618170. [PubMed: 22623779]

113. Angelosanto JM, Wherry EJ. Transcription factor regulation of CD8 ${ }^{+}$T-cell memory and exhaustion. Immunol. Rev. 2010; 236:167-175. [PubMed: 20636816]

114. Doering TA, et al. Network analysis reveals centrally connected genes and pathways involved in $\mathrm{CD}^{+} \mathrm{T}$ cell exhaustion versus memory. Immunity. 2012; 37:1130-1144. [PubMed: 23159438]

115. Lafferty KJ, Cunningham AJA. New analysis of allogeneic interactions. J. Immunol. 1975; 112:436-437. [PubMed: 4855833] Lafferty and Cunningham extended the Bretscher and Cohn two-signal model to suggest that $\mathrm{T}$ cells require two signals for activation.

116. Linsley PS, Clark EA, Ledbetter JA. T-cell antigen CD28 mediates adhesion with B cells by interacting with activation antigen B7/BB-1. Proc. Natl Acad. Sci. USA. 1990; 87:5031-5035. [PubMed: 2164219] This paper identified B7-1 as a ligand for CD28.

117. Linsley PS, et al. CTLA-4 is a second receptor for the B cell activation antigen B7. J. Exp. Med. 1991; 174:561-569. [PubMed: 1714933] CTLA4 was identified as a second receptor that interacts with $\mathrm{B} 7-1$ in this paper.

118. Azuma M, et al. B70 antigen is a second ligand for CTLA-4 and CD28. Nature. 1993; 366:76-79. [PubMed: 7694153] In this paper B7-2 was identified as a second ligand that interacts with both CD28 and CTLA4.

119. Hathcock KS, et al. Identification of an alternative CTLA-4 ligand costimulatory for T cell activation. Science. 1993; 262:905-907. [PubMed: 7694361] This paper and reference 11 identified B7-2 as a second ligand that interacts with CTLA.

120. Hathcock KS, Laszlo G, Pucillo C, Linsley P, Hodes RJ. Comparative analysis of B7-1 and B7-2 costimulatory ligands: expression and function. J. Exp. Med. 1994; 180:631-640. [PubMed: 7519245] 
121. Inaba K, et al. The tissue distribution of the B7-2 costimulator in mice: abundant expression on dendritic cells in situ and during maturation in vitro. J. Exp. Med. 1994; 180:1849-1860. [PubMed: 7525841]

122. Saito T, Yamasaki S. Negative feedback of T cell activation through inhibitory adapters and costimulatory receptors. Immunol. Rev. 2003; 192:143-160. [PubMed: 12670402]

123. Fos C, et al. ICOS ligation recruits the p50a PI3K regulatory subunit to the immunological synapse. J. Immunol. 2008; 181:1969-1977. [PubMed: 18641334]

124. Weiner LM, Surana R, Wang S. Monoclonal antibodies: versatile platforms for cancer immunotherapy. Nature Rev. Immunol. 2010; 10:317-327. [PubMed: 20414205]

125. Mellman I, Coukos G, Dranoff G. Cancer immunotherapy comes of age. Nature. 2011; 480:480489. [PubMed: 22193102]

126. Linsley PS, Nadler SG. The clinical utility of inhibiting CD28-mediated costimulation. Immunol. Rev. 2009; 229:307-321. [PubMed: 19426230] This review provides an interesting historical perspective of the elucidation of the CD28-B7 pathway, the development of CTLA4Ig, and the progression of CTLA4Ig to US Food and Drug Administration approval as a treatment for rheumatoid arthritis.

127. Larsen CP, et al. Rational development of LEA29Y (belatacept), a high-affinity variant of CTLA4-Ig with potent immunosuppressive properties. Am. J. Transplant. 2005; 5:443, 453. [PubMed: 15707398]

128. Pardoll DM. The blockade of immune checkpoints in cancer immunotherapy. Nature Rev. Cancer. 2012; 12:252-264. [PubMed: 22437870]

129. Topalian SL, et al. Safety, activity, and immune correlates of anti-PD-1 antibody in cancer. N. Engl. J. Med. 2012; 366:2443-2454. [PubMed: 22658127]

130. Ascierto PA, Simeone E, Sznol M, Fu YX, Melero I. Clinical experiences with anti-CD137 and anti-PD1 therapeutic antibodies. Semin. Oncol. 2010; 37:508-516. [PubMed: 21074066]

131. Vanneman M, Dranoff G. Combining immunotherapy and targeted therapies in cancer treatment. Nature Rev. Cancer. 2012; 12:237-251. [PubMed: 22437869]

132. Curran KJ, Pegram HJ, Brentjens RJ. Chimeric antigen receptors for T cell immunotherapy: current understanding and future directions. J. Gene Med. 2012; 14:405-415. [PubMed: 22262649]

133. Humphrey RW, et al. Opportunities and challenges in the development of experimental drug combinations for cancer. J. Natl Cancer Inst. 2011; 103:1222-1226. [PubMed: 21765011]

134. Marabelle A, Caux C. Immunobiology combined targeted and immunotherapy: the future of personalized medicine. Blood. 2012; 120:4454-4455. [PubMed: 23197581] 


\section{Box 1}

\section{The B7-CD28 co-signalling paradigm}

The classical two-signal hypothesis posited that both antigen and secondary stimuli are required for $\mathrm{T}$ cell activation ${ }^{115}$. The identification of the co-stimulatory receptor $\mathrm{CD} 28$ and a ligand, B7-1, illustrated the proposed model ${ }^{1,116}$ (see the figure). With the subsequent identification of a co-inhibitory receptor (cytotoxic T lymphocyte antigen 4 (CTLA4), which also binds to B7-1) and a second ligand (B7-2, which binds to both CD28 and CTLA4), the two-signal model had already begun to evolve into a more complex regulatory system ${ }^{117-119}$. CD28 is constitutively expressed on the cell surface of naive $\mathrm{CD} 4^{+}$and $\mathrm{CD} 8^{+} \mathrm{T}$ cells, and provides an essential co-stimulatory signal for $\mathrm{T}$ cell growth and survival upon ligation by B7-1 and B7-2 on antigen-presenting cells $(\mathrm{APCs})^{48}$. CTLA4 is induced following T cell activation and suppresses $\mathrm{T}$ cell responses ${ }^{48}$. When CTLA4 is upregulated, CD28 expression is subsequently downregulated by endocytosis ${ }^{48}$. Expression of B7-1 and B7-2 is modulated by the activation state of the APC. B7-2 is constitutively expressed on APCs at low levels, and infection, stress and cellular damage recognition by innate receptors activate APCs and induce transcription, translation and transportation of both B7-1 and B7-2 to the cell surface $^{120,121}$. Therefore, the modulation of both receptors and ligands on $\mathrm{T}$ cells and APCs, respectively, provides multiple levels of regulation for T cell activation to promote $\mathrm{T}$ cell responses against non-self antigens while preventing or limiting aberrant and autoreactive $\mathrm{T}$ cell responses. IDO, indoleamine 2,3-dioxygenase.

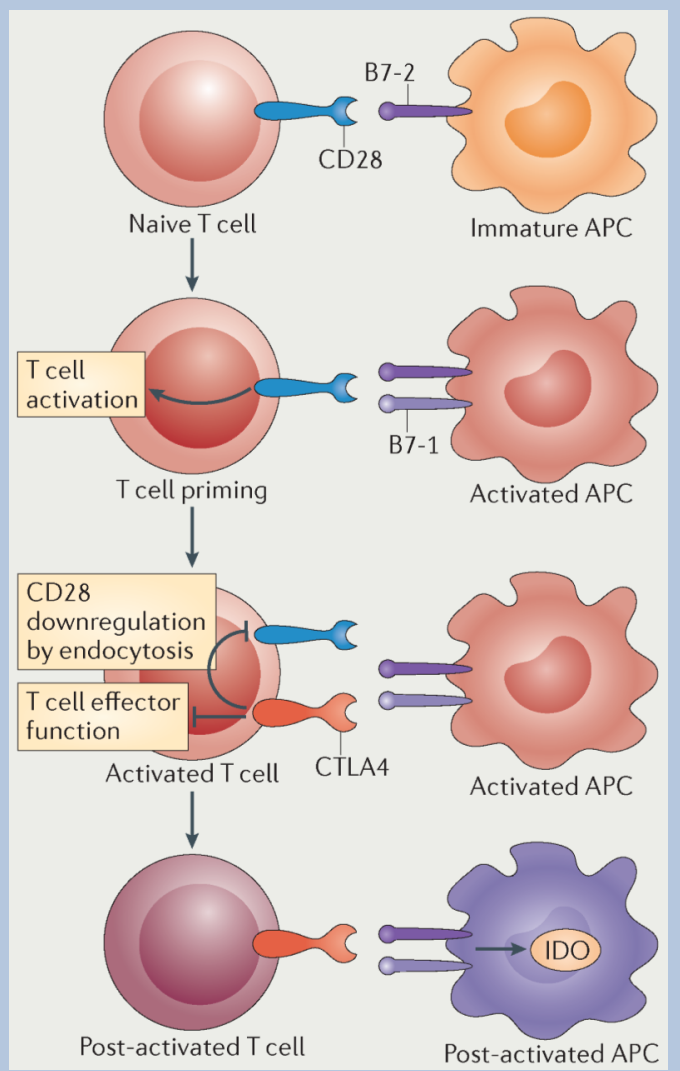




\section{Box 2}

\section{T cell receptor signalling and the immune synapse}

The spatial organization of co-signalling receptors on naive $\mathrm{T}$ cells is thought to be somewhat random; therefore specific events involving the reorganization of $\mathrm{T}$ cell surface molecules are required for optimal functional interactions to occur. The formation of the immune synapse is the primary reorganizing event that enables productive $\mathrm{T}$ cell receptor (TCR) signalling and co-signalling ${ }^{5}$. The immune synapse is composed of the central, peripheral and distal supra-molecular activation complexes (cSMAC, pSMAC and dSMAC, respectively), which contain specific molecules that are crucial for immune synapse formation and function ${ }^{5}$ (see the figure, part a). Imaging studies have shown that in the cSMAC, CD28 forms microclusters with the TCR, and these microclusters initiate the recruitment of signalling molecules and $\mathrm{T}$ cell activation ${ }^{5}$. Two cytoplasmic motifs of the CD28, namely YMNM and PYAP, are essential for lipid raft formation and localization of CD28 at the immunological synapse, as well as for recruitment and activation of protein kinase $\mathrm{C} \theta(\mathrm{PKC} \theta)$ and RAS guanyl nucleotide-releasing protein $(\text { RASGRP })^{42,43}$. Following activation, additional co-stimulatory molecules as well as coinhibitory receptors are recruited to the immune synapse $\mathrm{e}^{5,42,122,123}$. Cytotoxic $\mathrm{T}$ lymphocyte antigen 4 (CTLA4) accumulates in the same region of the cSMAC as CD28 to physically exclude CD28 from the $\mathrm{cSMAC}^{52}$ (see the figure, part b). CTLA4 also disrupts positive signalling through recruitment of phosphatases to the immunological synapse and subsequent dephosphorylation of key signalling molecules ${ }^{122}$. Similarly, it was recently shown that localization of programmed cell death 1 (PD1) to the immune synapse may result in dephosphorylation of TCR signalling components ${ }^{51}$. GRB2, growth factor receptor-bound protein 2; LAT, linker for activation of T cells; LCK, lymphocyte cell-specific protein-tyrosine kinase; LFA1, lymphocyte function-associated antigen 1 (also known as aL $\beta 2$ integrin); PI3K, phosphatidylinositol 3-kinase; PLCY, phospholipase CY; SLP76, SH2 domain-containing leukocyte protein of $76 \mathrm{kDa}$ (also known as LCP2); ZAP70, $70 \mathrm{kDa}$ zeta-chain associated protein.

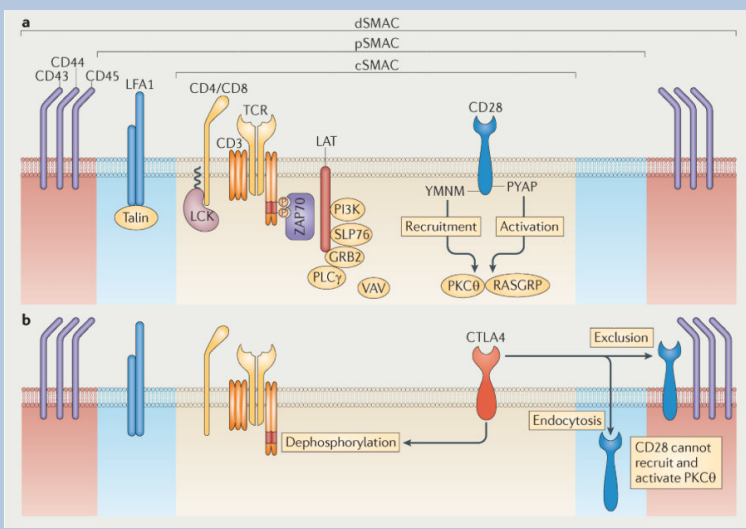




\section{Box 3}

\section{Immunotherapy targeting T cell co-signalling}

Immunotherapy that targets $\mathrm{T}$ cell co-signalling is now a major sub-field of immunotherapy ${ }^{124,125}$. The successful use of cytotoxic T lymphocyte antigen 4 (CTLA4) fusion proteins (CTLA4Ig, clinically known as abatacept (Orencia; Bristol-Myers Squibb) and belatacept (Nulojix; Bristol-Myers Squibb)) for the treatment of rheumatoid arthritis represents an important milestone in this field ${ }^{126,127}$. The recent promising results of clinical trials implementing programmed cell death 1 (PD1)- and B7-H1specific monoclonal antibodies in cancer therapy and the recent approval of CTLA4specific monoclonal antibodies (ipilimumab (Yervoy; Bristol-Myers Squibb)) for the treatment of patients with cancer by the US Food and Drug Administration provided clear evidence for the efficacy of co-signalling immunotherapy ${ }^{128,129}$. These recent successes have provided impetus for therapeutically targeting many co-stimulatory and co-inhibitory molecules, including 4-1BB, OX40, glucocorticoid-induced TNFR-related protein (GITR), lymphocyte activation gene 3 protein (LAG3), type I transmembrane (or T cell) immunoglobulin and mucin 3 (TIM3), B7-H4 and B7-H3 (REFS 128,130,131).

Understanding the fundamental mechanism of $\mathrm{T}$ cell co-signalling is essential for the design of co-signalling immunotherapy. Manipulation of a co-signalling molecule has differential effects in specific T cell subsets. For example, CTLA4 blockade enhances $\mathrm{CD}^{+}$effector $\mathrm{T}$ cell activity while inhibiting regulatory $\mathrm{T}$ cell-dependent immunosuppression ${ }^{128}$. Moreover, targeting of co-signalling molecules that are involved in bi-directional signalling or that are expressed on other cell types in addition to $\mathrm{T}$ cells (such as herpes virus entry mediator (HVEM), PD1, B7-H1, B7-1 (FIG. 1) and TIM molecules that are also expressed on antigen-presenting cells) may have unexpected outcomes. Importantly, new strategies are being devised to target one or more cosignalling molecules in combination therapies. These combination strategies include but are not limited to: targeting additional surface molecules (such as endothelial growth factor receptor and vascular endothelial growth factor), targeting specific signalling molecules (such as signal transducer and activator of transcription 3 (STAT3), BRAF and phosphatidylinositol 3-kinase (PI3K)), cell-based vaccination strategies (for example, based on dendritic cells and chimeric antigen receptor T cells) or more traditional therapies (such as radiotherapy or chemotherapy) ${ }^{125,131-134}$.

Understanding basic molecular mechanisms of co-stimulation and co-inhibition is crucial to the success of complex new combination therapies. 

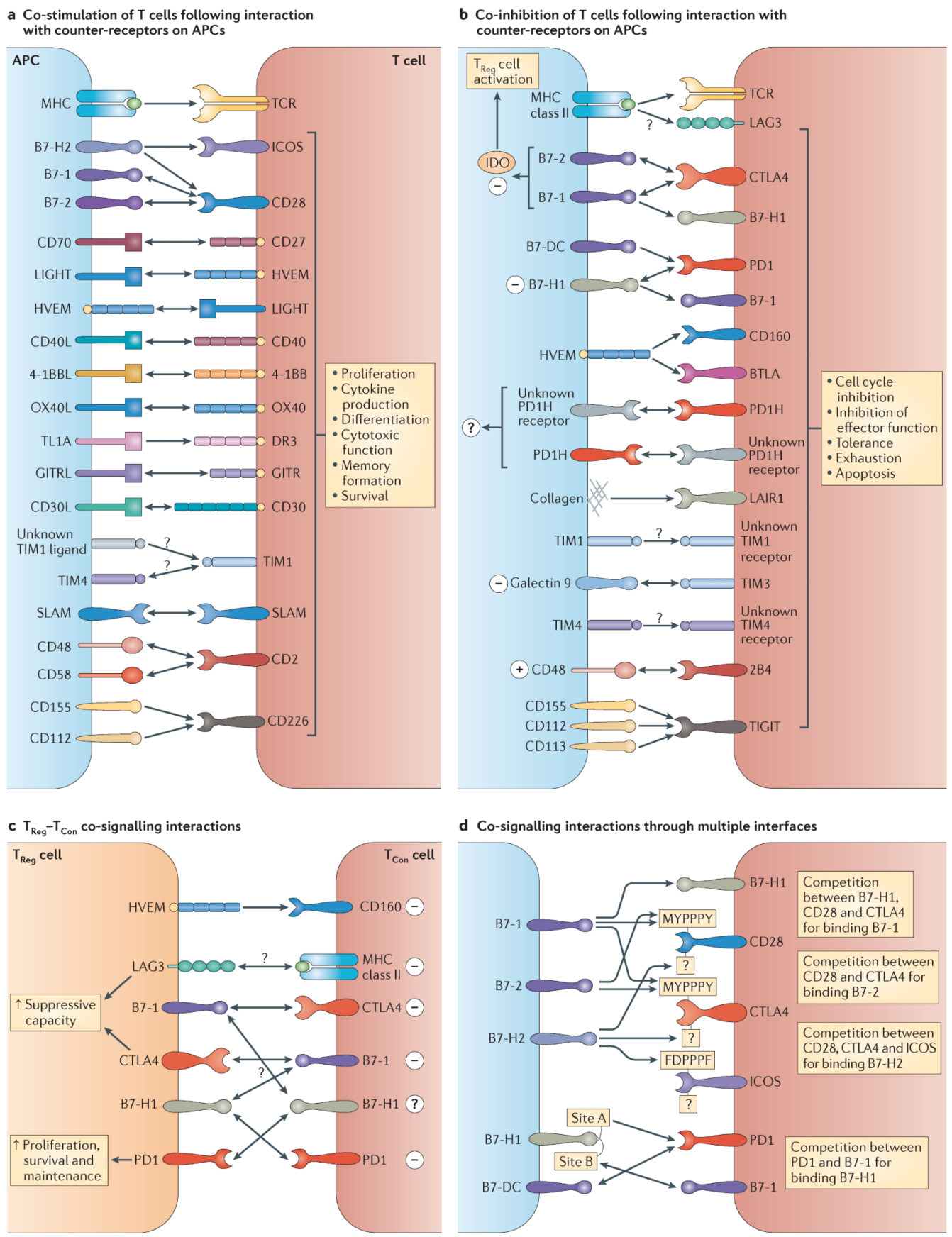

Figure 1. Co-signalling interactions in $\mathbf{T}$ cells

a|Co-stimulatory molecules deliver positive signals to $\mathrm{T}$ cells following their engagement by ligands and counter-receptors on antigen-presenting cells (APCs). Several co-stimulatory molecule interactions are bidirectional. b|Co-inhibitory molecules deliver negative signals into T cells. Cytotoxic T lymphocyte antigen 4 (CTLA4) is involved in bi-directional interactions: it inhibits T cell function after binding B7-1 and B7-2, and CTLA4-bound B7-1 and B7-2 may induce the expression of indoleamine 2,3-dioxygenase (IDO), which acts in trans to suppress activation of conventional $\mathrm{T}\left(\mathrm{T}_{\mathrm{Con}}\right)$ cells and promote the function of regulatory $\mathrm{T}\left(\mathrm{T}_{\mathrm{Reg}}\right)$ cells. $\mathbf{c} \mid \mathrm{In}_{\mathrm{Con}}-\mathrm{T}_{\mathrm{Reg}}$ cell interactions, unidirectional co-signalling primarily inhibits $\mathrm{T}_{\mathrm{Con}}$ cell reactivity, whereas bi-directional co-signalling may 
simultaneously deliver inhibitory signals to $\mathrm{T}_{\mathrm{Con}}$ cells and positive signals to $\mathrm{T}_{\mathrm{Reg}}$ cells. Herpes virus entry mediator (HVEM) functions as a co-stimulatory receptor on $\mathrm{T}_{\mathrm{Con}}$ cells, but on $\mathrm{T}_{\text {Reg }}$ cells it can interact with B and T lymphocyte attenuator (BTLA) or CD160 to deliver inhibitory signals. Lymphocyte activation gene 3 protein (LAG3) and CTLA4 expressed on $\mathrm{T}_{\text {Reg }}$ cells inhibit $\mathrm{T}_{\text {Con }}$ cells, while also enhancing the suppressive function of $\mathrm{T}_{\text {Reg }}$ cells. Programmed cell death 1 (PD1) on $\mathrm{T}_{\text {Con }}$ cells is inhibitory, whereas PD1 on $\mathrm{T}_{\text {Reg }}$ cells provides signals that may enhance $\mathrm{T}_{\mathrm{Reg}}$ cell proliferation, survival and maintenance. The role of B7-1 and B7-H1 on $\mathrm{T}_{\text {Reg }}$ cells and their role in $\mathrm{T}_{\mathrm{Con}}-\mathrm{T}_{\mathrm{Reg}}$ interactions is unclear. $\mathbf{d} \mid$ Co-signalling interactions through multiple interfaces. B7-H1, CD28 and CTLA4 all interact with B7-1. Similarly, CD28, CTLA4 and inducible T cell co-stimulator (ICOS) seem to compete for interactions with B7-2. B7-1 and B7-2 both bind the proline-rich motif MYPPPY on CD28 and CTLA4. In humans, B7-H2 can also interact with CD28 and CTLA4 through a second unique site, allowing both CD28 and CTLA4 to potentially interact with B7-1 or B7-2 and B7-H2 simultaneously. CD28, CTLA4 and ICOS all bind a similar site on B7-H2. B7-H1 and B7-DC both interact with a similar binding site on PD1. In addition, B7-H1 can also interact with B7-1. The site of B7-H1 that interacts with B7-1 (site $\mathrm{A}$ ) is distinct from that interacting with PD1 (site B), although overlapping residues may be used for both interactions. 4-1BBL, 4-1BB ligand; CD40L, CD40 ligand; DR3, death receptor 3; GITR, glucocorticoid-induced TNFR-related protein; GITRL, GITR ligand; LAIR1, leukocyte-associated immunoglobulin-like receptor 1; OX40L, OX40 ligand; PD1H, PD1 homologue; SLAM, signalling lymphocytic activation molecule; TCR, T cell receptor; TIGIT, T cell immunoreceptor with immunoglobulin and ITIM domains; TIM, type I transmembrane (or T cell) immunoglobulin and mucin; TL1A, TNF-like ligand A. 


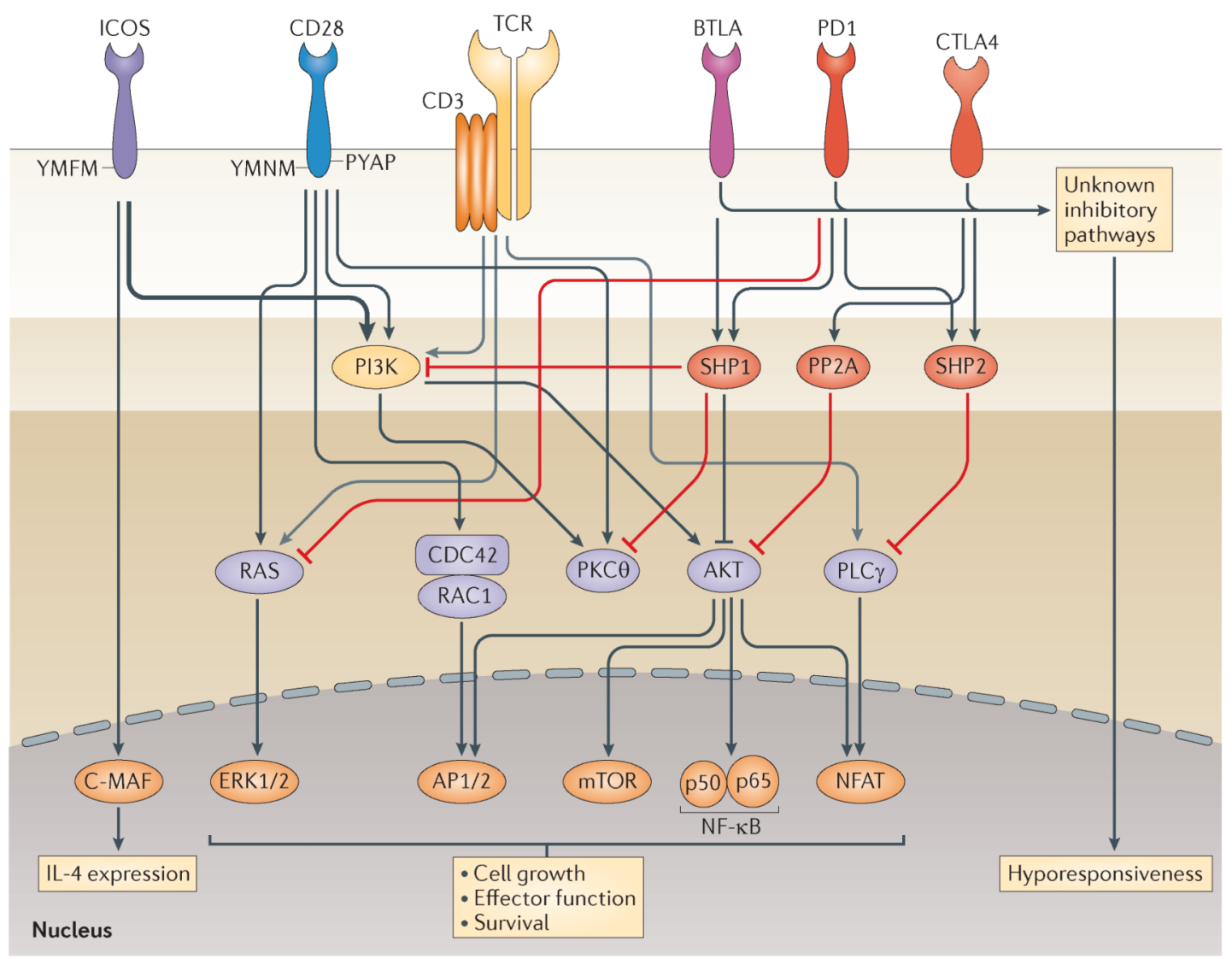

Figure 2. Co-stimulatory and co-inhibitory signalling pathways downstream of CD28 family receptors

Primary nodes of signalling activity downstream of T cell receptor (TCR)-CD3 and CD28 and inducible T cell co-stimulator (ICOS) co-stimulatory receptors overlap significantly. CD28 associates with proximal signalling molecules through the YMNM and PYAP motifs to co-stimulate several major signalling nodes, leading to activation of distal pathways involved in cell growth, activation of effector function and survival. ICOS lacks a PYAP motif but contains a YMFM motif that recruits the more active phosphatidylinositol 3-kinase (PI3K) subunit p50a (indicated by a thick arrow), thus leading to enhanced AKT signalling. ICOS also induces interleukin-4 (IL-4) through a C-MAF pathway. Co-inhibitory signalling downstream of B and T lymphocyte attenuator (BTLA), programmed cell death 1 (PD1) and cytotoxic T lymphocyte antigen 4 (CTLA4) suppresses T cell activation and function through the recruitment of the phosphatases $\mathrm{SH} 2$ domain-containing tyrosine phosphatase 1 (SHP1), SHP2 and serine/threonine protein phosphatase 2A (PP2A). These phosphatases dephosphorylate several of the major signalling nodes that are essential for co-stimulation of T cells. PD1 has also been shown to inhibit the RAS-extracellular signal-regulated kinase (ERK) pathway. Additional co-inhibitory pathways have been posited for CTLA4, PD1 and BTLA. BTLA and CTLA4 may also transduce positive signals in some contexts. BTLA may associate with growth factor receptor-bound protein 2 (GRB2) to activate PI3K and promote T cell survival, whereas CTLA4 may also activate PI3K through a YVKM motif. AP, activator protein; mTOR, mammalian target of rapamycin; NF- $\mathrm{B}$, nuclear factor-kB; NFAT, nuclear factor of activated T cells; PKC $\theta$, protein kinase $\mathrm{C} \theta$, PLC $\gamma$, phospholipase Cy. 


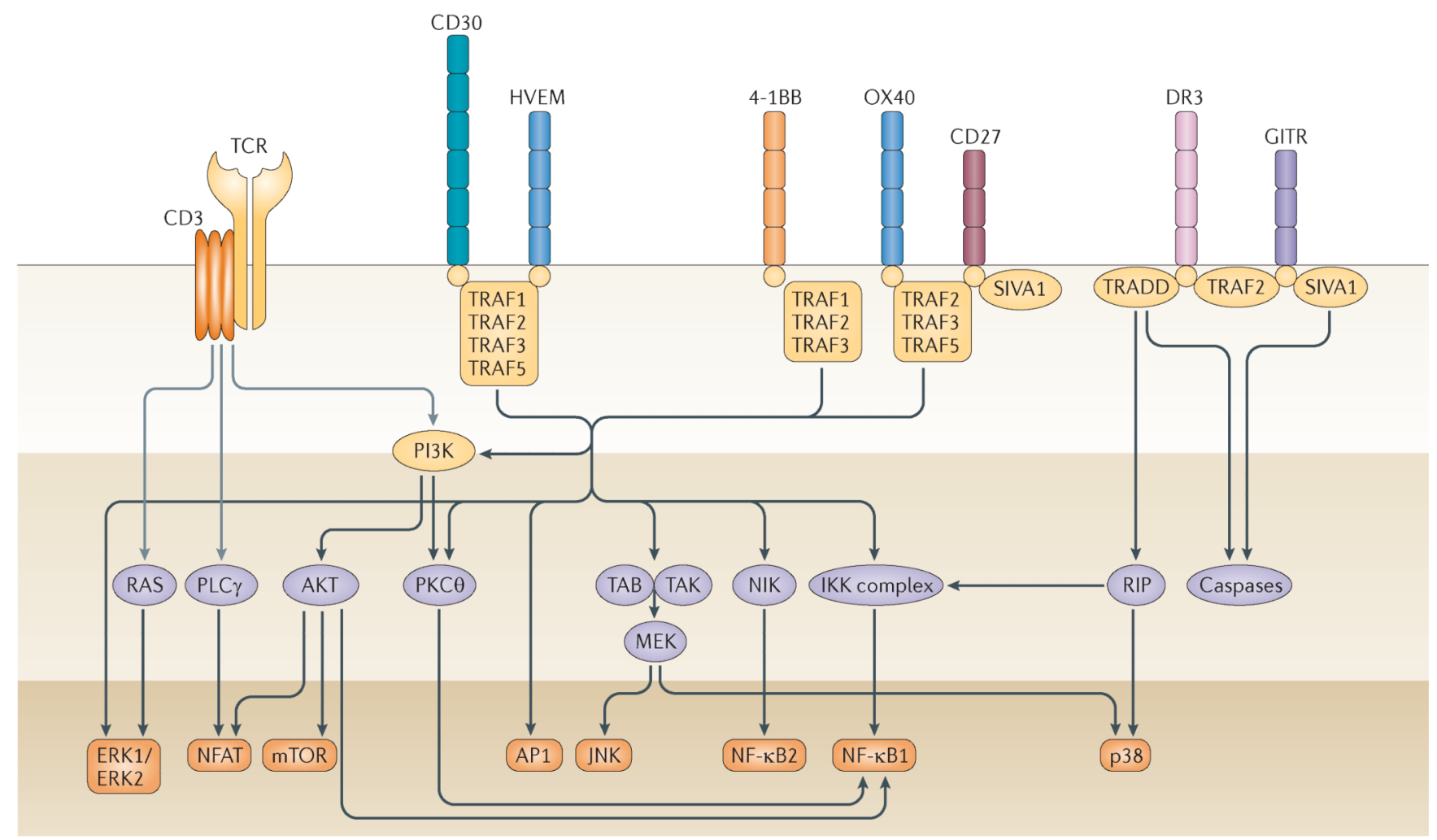

Figure 3. Co-signalling pathways downstream of tumour necrosis factor receptor superfamily receptors

Tumour necrosis factor (TNF) receptor superfamily (TNFRSF) receptors associate with proximal TNF receptor-associated factor (TRAF) adaptor molecules to activate primary signalling nodes that in turn activate the distal pathways that synergize with $\mathrm{T}$ cell receptor (TCR)-CD3 signalling pathways, resulting in enhanced cell growth, effector function and survival. Unique functions associated with TNFRSF receptors have yet to be clearly correlated with specific TRAFs in many cases. However, TRAF2 is the prototypical TRAF and is involved in c-Jun N-terminal kinase (JNK) activation, nuclear factor- $\mathrm{KB}$ (NF-KB) activation and anti-apoptotic signalling. TRAF5 also mediates NF-KB activation, and TRAF1 and TRAF3 also function in T cell co-stimulation and anti-apoptotic signalling. Death receptor 3 (DR3) associates with the adaptor molecule TNFR-associated death domain (TRADD), which recruits a TRAF2-receptor-interacting protein (RIP) complex that activates both NF-KB and mitogen-activated protein kinase (MAPK) signalling pathways. CD27 and glucocorticoid-induced TNFR-related protein (GITR) share the ability to associate with SIVA1, a molecule involved in apoptotic pathways, although the functional role of SIVA1 association is unclear, as CD27 and GITR function primarily as costimulatory molecules. The TNF receptors 4-1BB and OX40 have been shown to promote memory T cell function in the absence of TCR signalling, although the requirement of specific TRAFs and signalling pathways remains unclear. As such, it is possible that unknown adaptor molecules and/or signalling pathways remain to be identified. AP1, activator protein 1; ERK, extracellular signal-regulated kinase; HVEM, herpes virus entry mediator; IKK, inhibitor of NF-кB kinase; MEK, MAPK/ERK kinase; mTOR, mammalian target of rapamycin; NFAT, nuclear factor of activated T cells; NIK, NF-KB-inducing kinase; PI3K, phosphatidylinositol 3-kinase; PKC $\theta$, protein kinase $\mathrm{C} \theta$, PLCץ, phospholipase Cy; TAB, TAK1-binding protein; TAK, TGF $\beta$-activated kinase. 
Table 1

Co-stimulatory and co-inhibitory receptor function in stages of $\mathbf{T}$ cell differentiation

\begin{tabular}{|c|c|c|c|c|c|c|c|c|}
\hline Receptor & T cell type & Priming & Cell growth & $\begin{array}{l}T_{H} \text { cell } \\
\text { differentiation }\end{array}$ & $\begin{array}{l}\text { Effector } \\
\text { function }\end{array}$ & Survival & Memory & Refs \\
\hline \multirow[t]{2}{*}{$\mathrm{CD} 28$} & $\mathrm{CD}^{+}{ }^{+}$ & $(+)$ & $(+)$ & ND & ND & $(+)$ & $(+)$ & 48 \\
\hline & $\mathrm{CD} 8^{+}$ & $(+)$ & $(+)$ & ND & ND & $(+)$ & $(+)$ & \\
\hline \multirow[t]{2}{*}{ ICOS } & $\mathrm{CD}^{+}$ & ND & $(+)$ & $(+)$ & $(+)$ & $(+)$ & $(+)$ & 44 \\
\hline & $\mathrm{CD} 8^{+}$ & ND & $\mathrm{ND}$ & ND & $\mathrm{ND}$ & $(+)$ & $(+)$ & \\
\hline \multirow[t]{2}{*}{ CTLA4 } & $\mathrm{CD}^{+}$ & ND & $(-)$ & ND & $(-)$ & $(-)$ & $(-)$ & 48,84 \\
\hline & $\mathrm{CD} 8^{+}$ & ND & $(-)$ & ND & $(-)$ & $(-)$ & $(-)$ & \\
\hline \multirow[t]{2}{*}{ PD1 } & $\mathrm{CD}^{+}$ & ND & $(-)$ & ND & $(-)$ & $(-)$ & & 38 \\
\hline & $\mathrm{CD} 8^{+}$ & ND & $(-)$ & ND & $(-)$ & $(-)$ & $(-)$ & \\
\hline \multirow[t]{2}{*}{ BTLA } & $\mathrm{CD} 4^{+}$ & ND & ND & $\mathrm{ND}$ & $(-)$ & $(-)$ & $(+/-)$ & 22,94 \\
\hline & $\mathrm{CD}^{+}$ & $(-)$ & $(-)$ & ND & $(-)$ & $(-)$ & $(+/-)$ & \\
\hline \multirow[t]{2}{*}{ HVEM } & $\mathrm{CD}_{4}{ }^{+}$ & $(+)$ & $(+)$ & ND & $(+)$ & $(+)$ & $(+)$ & 22,62 \\
\hline & $\mathrm{CD}^{+}$ & $(+)$ & $(+)$ & ND & $(+)$ & ND & $(+)$ & \\
\hline \multirow[t]{2}{*}{ CD27 } & $\mathrm{CD}^{+}$ & $(+)$ & $(+)$ & $(+)$ & $(+)$ & $(+)$ & $(+)$ & 71,96 \\
\hline & $\mathrm{CD} 8^{+}$ & $(+)$ & $(+)$ & $\mathrm{ND}$ & $\mathrm{ND}$ & $(+)$ & $(+)$ & \\
\hline \multirow[t]{2}{*}{$4-1 \mathrm{BB}$} & $\mathrm{CD}^{+}{ }^{+}$ & $\mathrm{ND}$ & $(+)$ & $\mathrm{ND}$ & $(+)$ & $(+)$ & $(+)$ & 63,96 \\
\hline & $\mathrm{CD}^{+}$ & $\mathrm{ND}$ & $(+)$ & $\mathrm{ND}$ & $(+)$ & $(+)$ & $(+)$ & \\
\hline \multirow[t]{2}{*}{$0 \mathrm{X} 40$} & $\mathrm{CD}_{4}^{+}$ & ND & $(+)$ & $(+)$ & $(+)$ & $(+)$ & $(+)$ & $65,96,99$ \\
\hline & $\mathrm{CD} 8^{+}$ & ND & $(+)$ & ND & $(+)$ & $(+)$ & $(+)$ & \\
\hline \multirow[t]{2}{*}{ DR3 } & $\mathrm{CD} 4^{+}$ & ND & $(+)$ & $(+)$ & $(+)$ & ND & $(+)$ & 80 \\
\hline & $\mathrm{CD} 8^{+}$ & ND & $(+)$ & ND & ND & ND & ND & \\
\hline \multirow[t]{2}{*}{ GITR } & $\mathrm{CD}^{+}{ }^{+}$ & $\mathrm{ND}$ & $(+)$ & $\mathrm{ND}$ & $\mathrm{ND}$ & ND & $\mathrm{ND}$ & 64 \\
\hline & $\mathrm{CD}^{+}$ & ND & $(+)$ & $\mathrm{ND}$ & $(+)$ & ND & ND & \\
\hline \multirow[t]{2}{*}{$\mathrm{CD} 30$} & $\mathrm{CD}^{+}$ & $\mathrm{ND}$ & $(+)$ & $(+)$ & $\mathrm{ND}$ & ND & $\mathrm{ND}$ & $61,62,83$ \\
\hline & $\mathrm{CD}^{+}$ & $\mathrm{ND}$ & $(+)$ & $\mathrm{ND}$ & $\mathrm{ND}$ & $(+)$ & $(+)$ & \\
\hline \multirow[t]{2}{*}{ SLAM } & $\mathrm{CD} 4^{+}$ & ND & ND & $(+)$ & $(+)$ & ND & ND & 13 \\
\hline & $\mathrm{CD} 8^{+}$ & ND & $\mathrm{ND}$ & $\mathrm{ND}$ & $(+)$ & ND & ND & \\
\hline \multirow[t]{2}{*}{$\mathrm{CD} 2$} & $\mathrm{CD} 4^{+}$ & $(+)$ & $(+)$ & ND & $(+)$ & ND & $(+)$ & 73,74 \\
\hline & $\mathrm{CD} 8^{+}$ & $(+)$ & $(+)$ & ND & $(+)$ & ND & $(+)$ & \\
\hline \multirow[t]{2}{*}{$2 \mathrm{~B} 4$} & $\mathrm{CD}_{4}^{+}$ & ND & ND & ND & $\mathrm{ND}$ & ND & ND & 94,101 \\
\hline & $\mathrm{CD} 8^{+}$ & ND & $(+)$ & ND & $(+/-)$ & ND & ND & \\
\hline \multirow[t]{2}{*}{ TIM1 } & $\mathrm{CD}^{+}{ }^{+}$ & ND & $(+/-)$ & $(+/-)$ & $(+)$ & ND & ND & 11 \\
\hline & $\mathrm{CD}^{+}$ & ND & ND & ND & ND & ND & ND & \\
\hline \multirow[t]{2}{*}{ TIM2 } & $\mathrm{CD}^{+}$ & $\mathrm{ND}$ & $\mathrm{ND}$ & $(+)$ & $(+)$ & ND & ND & 11 \\
\hline & $\mathrm{CD}^{+}$ & ND & ND & ND & ND & ND & ND & \\
\hline
\end{tabular}




\begin{tabular}{|c|c|c|c|c|c|c|c|c|}
\hline Receptor & T cell type & Priming & Cell growth & $\begin{array}{l}T_{H} \text { cell } \\
\text { differentiation }\end{array}$ & $\begin{array}{l}\text { Effector } \\
\text { function }\end{array}$ & Survival & Memory & Refs \\
\hline \multirow[t]{2}{*}{ TIM3 } & $\mathrm{CD} 4^{+}$ & ND & $(-)$ & $(-)$ & $(-)$ & ND & $(-)$ & 11 \\
\hline & $\mathrm{CD} 8^{+}$ & ND & $(-)$ & ND & $(-)$ & ND & $(-)$ & \\
\hline \multirow[t]{2}{*}{ TIGIT } & $\mathrm{CD}^{+}{ }^{+}$ & ND & $(-)$ & ND & $(-)$ & ND & ND & 20 \\
\hline & $\mathrm{CD}^{+}$ & ND & ND & ND & ND & ND & ND & \\
\hline \multirow[t]{2}{*}{ CD226 } & $\mathrm{CD} 4^{+}$ & ND & ND & ND & ND & ND & ND & 20 \\
\hline & $\mathrm{CD}^{+}$ & ND & $(+)$ & $(+)$ & $(+)$ & ND & ND & \\
\hline \multirow[t]{2}{*}{ CD160 } & $\mathrm{CD}^{+}{ }^{+}$ & ND & $(-)$ & ND & $(-)$ & $(-)$ & $(-)$ & $22,94,101$ \\
\hline & $\mathrm{CD} 8^{+}$ & ND & $(-)$ & ND & $(-)$ & ND & $(-)$ & \\
\hline \multirow[t]{2}{*}{ LAG3 } & $\mathrm{CD} 4^{+}$ & ND & $(-)$ & ND & $(-)$ & ND & ND & 94,101 \\
\hline & $\mathrm{CD} 8^{+}$ & ND & $(-)$ & ND & $(-)$ & ND & ND & \\
\hline \multirow[t]{2}{*}{ LAIR1 } & $\mathrm{CD}^{+}{ }^{+}$ & ND & $(-)$ & ND & $(-)$ & ND & ND & 21 \\
\hline & $\mathrm{CD} 8^{+}$ & ND & $(-)$ & ND & $(-)$ & ND & ND & \\
\hline \multirow[t]{2}{*}{ B7-1 } & $\mathrm{CD} 4^{+}$ & ND & $(-)$ & ND & $(-)$ & ND & ND & $34,35,88,89$ \\
\hline & $\mathrm{CD} 8^{+}$ & ND & $(-)$ & ND & $(-)$ & ND & ND & \\
\hline \multirow[t]{2}{*}{ B7-H1 } & $\mathrm{CD} 4^{+}$ & ND & $(-)$ & ND & $(-)$ & ND & ND & $34,35,89$ \\
\hline & $\mathrm{CD}^{+}$ & ND & $(-)$ & ND & $(-)$ & ND & ND & \\
\hline
\end{tabular}

'(+)' indicates positive function, '(-)' indicates negative function, and 'ND' indicates that either no function has been observed or the function has not been determined. BTLA, B and T lymphocyte attenuator; CTLA4, cytotoxic T lymphocyte antigen 4; DR3, death receptor 3; GITR, glucocorticoid-induced TNFR-related protein; HVEM, herpes virus entry mediator; ICOS, inducible T cell co-stimulator; LAG3, lymphocyte activation gene 3 protein; LAIR1, leukocyte-associated immunoglobulin-like receptor 1; PD1, programmed cell death 1; SLAM, signalling lymphocytic activation molecule; $\mathrm{T}_{\mathrm{H}}$, T helper; TIGIT, $\mathrm{T}$ cell immunoreceptor with immunoglobulin and ITIM domains; TIM, type I transmembrane (or T cell) immunoglobulin and mucin. 